\title{
Role of subsurface entrainment temperature (Te) in the onset of EI Niño events, as represented in an intermediate coupled model
}

\author{
Rong-Hua Zhang ${ }^{1}$ Chuan Gao ${ }^{1,2}$
}

Received: 14 February 2015 / Accepted: 11 May 2015 / Published online: 28 May 2015

(C) The Author(s) 2015. This article is published with open access at Springerlink.com

\begin{abstract}
An improved intermediate coupled model (ICM) is described for use in ENSO-related modeling in the tropical Pacific, with ten baroclinic modes included in the vertical and horizonatally varying stratification taken into account. One crucial component of the model is the way in which the subsurface entrainment temperature in the surface mixed layer $\left(\mathrm{T}_{\mathrm{e}}\right)$ is explicitly used to determine the sea surface temperature (SST) variability. An optimized procedure is developed to depict $T_{e}$ using inverse modeling from an SST anomaly equation and its empirical relationship with the sea surface pressure variability. The coupled system realistically produces interannual variability associated with ENSO cycles, with a dominant 4-year oscillation. The onset and development of El Niño events from this ICM are examined in view of the well-known delayed oscillator paradigm; an example is given for the evolution of La Niña conditions in model year 2 to El Niño conditions in year 4. Right after a La Niña event (e.g., in year 2), there is a clear signature of reflections at the western boundary in early year 2, with related equatorial signals propagating eastward along the equator into the eastern basin in middle year 2. However, these reflected signals on the equator do not directly lead to an onset of an El Niño event at that time. Instead, approximately 1-year delay, a major El Niño event is seen to develop in the following year (late year 3), at a time
\end{abstract}

Rong-Hua Zhang

rzhang@qdio.ac.cn

1 Key Laboratory of Ocean Circulation and Waves, Institute of Oceanology, Chinese Academy of Sciences, Qingdao 266071, China

2 University of Chinese Academy of Sciences, Beijing 100049, China when there is no reflected signal explicitly from the western boundary, indicating that the origin of the El Niño event cannot be directly ascribed to the reflection processes. Instead, Kelvin waves in the ocean that actually triggers the El Niño event in early year 3 are generated by interior wind anomalies near the date line that are associated with the first appearance of warm SST anomalies off the equator. Persisted $T_{e}$ anomalies off the equator in the western tropical Pacific initiate the warm SST anomaly near the date line along the North Equatorial Countercurrent region, which induces wind anomalies and an ocean-atmosphere coupling, leading to the El Niño event in year 4 . The relevance of these ICM-based results to other onset mechanisms of El Niño and observations is also discussed.

\section{Introduction}

The tropical Pacific is a region in which the El Niño and Southern Oscillation (ENSO) occurs frequently with a preferred 2-7-year period, inducing large-scale climate variability worldwide (e.g., Bjerknes 1969; Cane and Zebiak 1985). In recent decades, great progress has been made in ENSO mechanism understanding, theory development and numerical modeling. For example, positive feedbacks are identified that can explain the development of ENSO events involving interactions among the surface winds, sea surface temperature (SST) and the thermocline in the tropical Pacific (the thermocline feedback; e.g., Jin and An 1999). To interpret the ENSO's cyclic nature, various negative feedback processes have also been proposed, including a delayed oscillator paradigm associated with Rossby wave reflections at the western boundaries of the tropical Pacific (Schopf and Suarez 1988; Battisti and Hirst 1989). 
Various models with different complexities have been developed for ENSO studies, including intermediate coupled models (ICMs), hybrid coupled models (HCMs), and fully coupled general circulation models (GCMs). Coupled models can reasonably well depict the interannual variability that is associated with ENSO in the tropical Pacific (e.g., McCreary and Anderson 1991; Neelin et al. 1992; Ji et al. 1998). Nevertheless, the equatorial Pacific Ocean remains an area in which pronounced differences exist between observations and simulations, with systematic model biases. For example, obvious discrepancies exist in ocean GCM (OGCM) simulations, including a model thermocline that is too diffuse, with a weak vertical gradient of temperature (e.g., Zhang and Endoh 1992; Stockdale et al. 1993). Furthermore, OGCM-based coupled simulations commonly have an unrealistic structure of interannual SST variability with underestimated SST anomalies over the eastern equatorial Pacific. Additionally, the actual system is characterized by interannual oscillations with a main period of 4-5 years, but some coupled GCMs favor a quasibiennial oscillation accompanied by the predominance of the westward propagation of simulated SST anomalies over the eastern and central equatorial Pacific (e.g., Latif et al. 2001). Physically, processes that are not well represented in current OGCMs include subsurface thermal effects on SSTs in the central and eastern equatorial Pacific (e.g., Zhang and Zebiak 2002).

Subsurface thermal effects on SSTs are represented by vertical mixing/diffusion processes, which are associated with the temperature of subsurface waters entrained into the mixed layer $\left(\mathrm{T}_{\mathrm{e}}\right)$ and vertical diffusivity coefficients $\left(\mathrm{K}_{\mathrm{v}}\right)$. In ocean models, the vertical mixing/diffusion processes are generally parameterized using large-scale oceanic fields, with some adjustable parameters (e.g., $\mathrm{K}_{\mathrm{v}}$ ). Previously, great efforts have been exerted in determining how vertical diffusivity coefficients are determined, including the K profile parameterization (KPP)-scheme (Large and Gent 1999). Inevitably, uncertainties exist in estimating these coefficients that are used for ocean models. Note that model representations for subsurface thermal effects on SSTs through vertical mixing/diffusion terms are related to both the vertical diffusivity coefficients and the entrainment temperature $\left(\mathrm{T}_{\mathrm{e}}\right)$ fields. Indeed, various observations and modeling studies have indicated that the water entrainment into the surface layer through the base of the mixed layer is the primary process that is responsible for mean SST climatology and its variations in the tropical Pacific (e.g., Zebiak and Cane 1987; Kleeman 1993; DeWitte et al. 2002).

To improve SST simulations, we focused on the temperature of subsurface waters entrained into the mixed layer $\left(\mathrm{T}_{\mathrm{e}}\right)$. For instance, an optimized framework is developed to depict $T_{e}$ in two steps (Zhang et al. 2005a). First, inverse modeling is used to determine the $\mathrm{T}_{\mathrm{e}}$ using an SST anomaly equation, giving rise to a subsurface effect on SST that is balanced with the other terms in the heat budget of the mixed layer. Second, $T_{e}$ is parameterized from the sea surface pressure (SSP, which is equivalent to the sea level (SL)) variability because thermocline fluctuations are a major source of $T_{e}$ anomalies in the equatorial Pacific. Then, given an SSP anomaly, $\mathrm{T}_{e}$ can be optimally determined to calculate the SST anomalies. As this approach leads to an optimized representation of the $\mathrm{T}_{\mathrm{e}}$ fields in balancing other dominant terms influencing the SST budget, an improved SST simulation is achieved.

Then, we constructed an intermediate coupled model (ICM) consisting of a statistical atmospheric wind model, an intermediate dynamic ocean model that was developed by Keenlyside and Kleeman (2002), an SST anomaly model, and an $\mathrm{T}_{\mathrm{e}}$ model. The ICM can depict interannual variability very well with a dominant 4-year oscillation period (e.g., Zhang et al. 2003, 2005b). Since 2003, this model has been used for routine ENSO prediction with pronounced success (Zhang et al. 2013). In addition, this $\mathrm{T}_{\mathrm{e}}$-based framework has also been applied to OGCM-based HCM simulations and ENSO predictions (Zhu et al. 2011, 2012).

Although the ICM has been used for various modeling studies in the past decade (including the role of decadal $\mathrm{T}_{\mathrm{e}}$ variability in modulating ENSO and real-time ENSO prediction; Zhang and Busalacchi 2005; Zheng et al. 2007, 2009; Zhang et al. 2008), its detailed description is still lacking. In addition, the mechanisms for ENSO onset and development in this ICM have not been clearly delineated. Some specific questions remain to be addressed as follows. How is interannual variability generated in the ICM? What are the relationships among the oceanic and atmospheric anomalies that give rise to ENSO events? Are the ENSO processes that are represented in the ICM consistent with those that are described by the delayed oscillator mechanism? What is the role that is played by $T_{e}$ in the simulated ENSO evolution in the ICM?

This article is organized as follows. Section 2 describes the model and some of the observational data that are used in this work. Section 3 provides a description of the interannual variability as simulated in the ICM, followed by a heat budget analysis for the interannual SST variability in Sect. 4. A conclusion and discussion are given in Sect. 5.

\section{Description of an intermediate coupled model (ICM) and various data sets that were used}

An ICM is constructed for the tropical Pacific, consisting of an intermediate ocean model (IOM) and anomaly models for $T_{e}$, SST, and wind stress $(\tau)$. Readers can find more 
details regarding the IOM in Keenlyside and Kleeman (2002) and regarding an empirical $\mathrm{T}_{\mathrm{e}}$ model in Zhang et al. (2005a).

\subsection{An ocean dynamical model}

An intermediate ocean model was developed by Keenlyside and Kleeman (2002). The dynamical component of this model consists of linear and non-linear parts. The former is an extension of the McCreary (1981) modal model, with further consideration of the horizontally varying background stratification and partial non-linear contributions. Computationally, the linear component is solved through a modal decomposition approach in the vertical (ten baroclinic modes are retained, and the combined effects of higher baroclinic modes from 11 to 30 are included, and are represented only in the two surface layers). The non-linear components are highly simplified as residual terms in the momentum equations, taking into account corrections that are made to the solution where the linear assumption breaks down in the equatorial region. The non-linear part is solved only within two surface layers as forced by the linear part through nonlinear advection terms. The linear and non-linear components produce dynamic ocean fields, including horizontal currents in the surface mixed layer, vertical velocity at the base of the mixed layer (entrainment velocity), and ocean pressure fields.

The dynamical core of the ocean model has been designed such that the model run can be performed in either its full version (producing total ocean fields) or its anomaly version (directly producing an anomaly field relative to the prescribed ocean climatology). In its anomaly version, a model variable is separated into its climatological part and its interannual anomaly part. The former is obtained by forcing the ocean model using mean climatology winds; the latter is produced by the anomaly ocean model being forced directly by anomaly winds, with seasonally varying model climatological fields being specified.

The ocean model domain covers the tropical Pacific and Atlantic basins from $31.0^{\circ} \mathrm{S}$ to $31.0^{\circ} \mathrm{N}$ and from $124^{\circ} \mathrm{E}$ to $30^{\circ} \mathrm{E}$, with a realistic representation of continents (only the results from the tropical Pacific basin are presented in this study). This model has horizontal resolution of $2^{\circ}$ zonally and a varying grid meridionally (stretched from $0.5^{\circ}$ within $10^{\circ}$ of the equator to $3^{\circ}$ at the meridional northern and southern boundaries). Vertically, the ocean is assumed to have a 5500-m flat bottom. The linear component has 33 levels in the vertical at the standard ocean levels that are defined by Levitus (1982), with 8 levels in the upper $125 \mathrm{~m}$. The effects of the non-linearity and high-order baroclinic modes are considered only for two layers, which span the upper $125 \mathrm{~m}$ with a surface mixed layer whose depth is prescribed from the Levitus annual-mean temperature and salinity data in terms of a stability criterion.

\subsection{An SST anomaly model with an empirical representation of $T_{e}$}

An SST anomaly model is embedded into the ocean dynamical component. The governing equation of this model describes the evolution of interannual temperature anomalies over the surface mixed layer, driven by ocean horizontal and vertical advections due to both of the mean currents specified and the anomaly currents simulated directly from the ocean model. The depth of the surface mixed layer is spatially varying, and is prescribed as annual-mean field from the Levitus data. The surface heat flux is parameterized as being negatively proportional to local SST anomalies, with the thermal damping coefficients having a value of $100 \mathrm{day}^{-1}$. In order to close the SST equation, subsurface entrainment temperature $\left(T_{e}\right)$ fields need to be determined from other directly predicted ocean variables in the model.

Data analyses and modeling studies indicate that interannual variations in sea surface pressure (SSP, which is equivalent to sea level) and $\mathrm{T}_{\mathrm{e}}$ are well correlated over the tropical Pacific (e.g., Meinen and McPhaden 2000; Kumar and $\mathrm{Hu}$ 2014). The origin of these correlations is the strong influence of ocean dynamical adjustments on $\mathrm{T}_{e}$ (and SST) in the equatorial Pacific regions. The ocean dynamical adjustments in response to winds are characterized by the vertical displacement of the thermocline, which is a primary process that causes changes in the entrainment temperature at the base of the mixed layer. Thus, thermocline fluctuations can have a direct and immediate effect on $T_{e}$ in the equatorial Pacific. This understanding provides a physical guidance for developing a $T_{e}$ parameterization being represented as a response to changes in thermocline variability. We developed a non-local empirical scheme to parameterize $T_{e}$ in terms of thermocline variability. For example, a relationship between $\mathrm{T}_{\mathrm{e}}$ and SSP anomalies has been empirically derived from historical data (Zhang et al. 2005a).

As previously examined, $T_{e}$ is a major source for SST variability in the equatorial Pacific on interannual time scales. To optimize SST simulations with a given SST anomaly equation, we have developed an empirical procedure to represent the $T_{e}$ field for use in the ICM. First, a long-term $T_{e}$ anomaly field (e.g., from 1962 to 1998) is obtained from the inverse modeling of the SST anomaly equation in which the SST fields and its tendency are specified from observations and the mean and anomaly currents are modeled from the ocean model. Then, a relationship between $T_{e}$ and SSP (as obtained from ocean model simulation) is derived using a singular value decomposition (SVD) analysis, which is performed on all of the time series data regardless of seasonal variations (Chang et al. 2001; Zhang et al. 2005a). With the SVD technique, an SSP 
anomaly pattern (an ocean model variable) from ocean simulations can be projected onto the SSP component of the $\mathrm{T}_{\mathrm{e}}$-SSP modes with the first five SVD modes included. The corresponding $T_{e}$ anomalies are then estimated for use in the SST anomaly model. This $\mathrm{T}_{\mathrm{e}}$ parameterization presents an effective way to significantly improve the performance of the SST simulations because $T_{e}$ is a driving source for interannual SST variability, serving to represent subsurface effects that are associated with thermocline fluctuations.

Note that we emphasized the importance of $T_{e}$ in the ENSO evolution in which $T_{e}$ is statistically expressed by SSP in the model. As well known, SSP is largely associated with thermal condition of whole ocean column (or mixedlayer), and ocean subsurface entrainment across the thermocline layer is just one of processes affecting the thermal condition and $\mathrm{T}_{\mathrm{e}}$. In other word, through parameterizing $T_{e}$, the variation of thermal condition of the mixed-layer is introduced into the model. As indicated in the observations (e.g., Meinen and McPhaden 2000; Kumar and Hu 2014), the variation of thermal condition in the mixed-layer statistically leads Nino3.4 SST anomalies by 1-3 seasons. This non-local relationship with lead-lag correlation between the SSP and $T_{e}$ is well represented in the $T_{e}$ parameterization using statistical method based on historical data. Detailed discussion about the physics behind the $\mathrm{T}_{\mathrm{e}}$ parametrization can be found in Zhang et al. (2005a).

\subsection{A statistical atmospheric model for interannual wind stress $(\tau)$ anomalies}

The atmospheric model that was adopted in this work is also a statistical model, taking into account an empirical feedback response of wind stress $(\tau)$ to SST anomalies. This response is also estimated using an SVD of the covariance matrix as calculated from the observed time series of monthly mean SST and $\tau$ fields (e.g., Syu et al. 1995; Chang et al. 2001). In this study, we perform a combined SVD analysis of the covariance among the anomalies of SST and zonal and meridional wind stress. As previously demonstrated (e.g., Barnett et al. 1993), the performance of such statistical $\tau$ models depends on the seasonality of the surface wind variability. Two ways of such SVD analyses are tested in the statistical modeling of $\tau$. One SVD analysis is conducted on all of the time series data regardless of seasonal variability; therefore, we have one $\tau$ model for all calendar months. Another analysis is performed separately for each month to take into account seasonal variability; so we have $12 \tau$ models for the twelve calendar months (i.e., seasonally dependent models for January, February, etc.). Additionally, the model performance depends on factors, such as the truncation number for the retained SVD modes (e.g., Barnett et al. 1993; Syu et al. 1995). In the consideration of the sequence of the SVD singular values

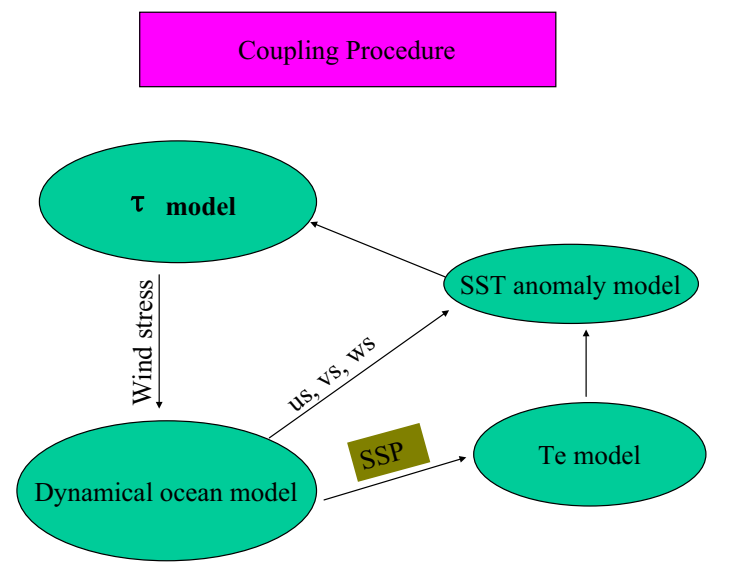

Fig. 1 A schematic diagram illustrating an intermediate coupled atmosphere-ocean model (ICM) consisting of an ocean dynamical model, an SST anomaly model, an empirical model to calculate anomalies of $\mathrm{T}_{\mathrm{e}}$ from those of SSP, and a statistical atmospheric model to calculate surface wind stress $(\tau)$

(Zhang et al. 2005a) and some reconstruction tests from the observed SST anomalies to reconstruct $\tau$ anomalies with a reasonable amplitude, the first SVD modes are retained. With the SVD technique, an SST anomaly field from ocean simulations can be projected onto the SST component of the constructed $\tau$-SST modes. The corresponding $\tau$ anomalies are then estimated to drive the ocean model.

\subsection{The coupling procedure}

Figure 1 illustrates the model components that exchange the anomaly fields within the coupled system. At each time step, the dynamical ocean model calculates anomalous current fields and ocean pressure fields (including SSP anomalies). Using the $T_{e}$ model, $T_{e}$ anomalies are estimated from the SSP anomaly. The dynamical ocean model produces the ocean current fields at the 33 standard vertical levels, which are used to obtain the corresponding currents over the surface mixed layer and anomalous vertical velocity at the base of the mixed layer. Then, SST anomalies are calculated using the simulated and prescribed oceanic currents, the $T_{e}$ anomalies and the prescribed climatology of the mean SST and vertical gradient of temperature. Using the $\tau$ model, the resultant SST anomaly is used to determine wind anomalies, which are used to force the ocean dynamical model. Information is exchanged once daily between the atmosphere $(\tau)$ and the ocean (SST); the $T_{e}$ anomaly field is also updated once daily from the SSP anomaly for use in the SST anomaly model. Note that interannual SST anomaly is directly produced from its anomaly model at each model time step. The ICM is initiated with an imposed westerly wind anomaly for eight months. The evolution of anomalous conditions thereafter 
is determined solely by the coupled ocean-atmosphere interactions in the system.

In this coupled system, the two dominant forcing fields ( $\tau$ for the ocean and $T_{e}$ for the SST) are both determined by SVD analyses. The amplitude of the calculated $T_{e}$ and $\tau$ variabilities can be further re-scaled. For example, as examined previously in numerous studies (e.g., Neelin and Jin 1993; Syu et al. 1995), coupled behaviors are sensitive to the so-called relative coupling coefficient $\left(\alpha_{\tau}\right)$, a scalar parameter that is introduced to reasonably represent the $\tau$ anomaly intensity from the atmospheric $\tau$ model. Similarly, the $T_{e}$ anomalies from the SVD-based $T_{e}$ model can be multiplied by a scalar parameter $\left(\alpha_{\mathrm{Te}}\right)$ that is referred to as the relative thermocline coefficient. Several tuning experiments have been performed with different values of $\alpha_{\tau}$ and $\alpha_{\mathrm{Te}}$ to examine the coupled variability. Values of $\alpha_{\tau}=1.0$ and $\alpha_{\mathrm{Te}}=1$ produce very strong anomalies in the model; values of $\alpha_{\tau}=0.87$ and $\alpha_{\mathrm{Te}}=1$ produce a reasonable interannual variability with an oscillation period of 4 years. A further decrease in $\alpha_{\tau}$ and $\alpha_{\mathrm{Te}}$ produces a damping oscillation, but the oscillation period does not alter very much. In this study, we show the most realistic results by taking $\alpha_{\tau}=0.87$ and $\alpha_{\mathrm{Te}}=1.0$ for numerical experiments.

\subsection{Observed and simulated data sets and analysis procedures}

Various data that were observed and simulated are used to construct the two empirical models for $\tau$ and $T_{e}$. The observed SST data are from Reynolds and Smith (1994). The wind stress anomaly data that were used to construct the SVD-based $\tau$ model are the 24-member ensemble mean from ECHAM4.5 AMIP runs, each of which is forced by observed SST anomalies from 1950 to 1999 . The ensemble mean data are used in an attempt to enhance the atmospheric response signals to external SST anomalies and to reduce the atmospheric noisy effect on the tropical coupled system. Interannual SSP anomaly fields are produced from an ocean-only integration from 1962 to 1999 that is forced by observed interannual wind stress anomalies from the NCEP/NCAR reanalysis (Kalnay et al. 1996). Interannual $T_{e}$ anomaly fields are estimated from an inverse modeling of the SST anomaly equation as follows. First, the dynamical ocean model is forced by climatological winds from the NCEP/NCAR reanalyses to obtain the mean current fields. Then, an interannual run is performed that is forced by the NCEP/NCAR wind anomalies, from which interannual ocean current and ocean pressure anomaly fields are obtained. Finally, the anomaly $\mathrm{T}_{\mathrm{e}}$ field is estimated from the inversion of the SST anomaly equation using observed SST fields and tendency from Reynolds and Smith (1994), and simulated mean and anomaly currents.

These observed and/or model-derived anomaly fields are used to construct the two empirical models $\left(T_{e}\right.$ and $\left.\tau\right)$.
For the $\mathrm{T}_{\mathrm{e}}$ model, the SVD analysis is performed between $\mathrm{T}_{\mathrm{e}}$ anomalies (from the inverse modeling) and SSP anomalies (from the ocean dynamical model) from 1963 to 1996 (totaling 34-years of data). For the $\tau$ model, the SVD analysis is performed during the same period between observed SST anomalies (Reynolds and Smith 1994) and $\tau$ anomalies (the 24-member ensemble mean from the ECHAM4.5 AMIP runs).

\section{Interannual variability}

The ICM can depict well the interannual variability that is associated with ENSO (Zhang et al. 2003, 2005b). When analyzing processes that give rise to El Niño events, it is found that the mechanism for El Niño onsets from this ICM is different from that indicated by the delayer oscillator paradigm which directly involves the reflection processes at the western boundary of the tropical Pacific (e.g., Schopf and Suarez 1988). Instead, a clear $\mathrm{T}_{\mathrm{e}}$ anomaly pattern is seen off and on the equator in the western tropical Pacific, which in due course acts to initiate a warm SST anomaly along the North Equatorial Countercurrent (NECC) path near the date line. As the SST anomalies are generated, wind anomalies can be reasonably considered as a corresponding response, thus inducing coupled interactions between the ocean and atmosphere in the ICM and leading to an onset of El Niño. These related analyses are presented in this section.

\subsection{The space-time evolution}

Figure 2 displays the time series of simulated SST anomalies for the Niño1 +2 and the Niño3 regions, and zonal wind stress anomalies for the Nino 4 region. The ICM depicts a pronounced interannual oscillation with an approximately 4-year period: warm and cold SST anomalies are sustainable approximately 1 year over the central and eastern equatorial Pacific. There is no clear phase lag between the SST variations at the Niño1 +2 and Niño3 regions.

Figures 3 and 4 present the longitude-time sections of interannual anomalies along the equator for SST, zonal wind stress, sea surface pressure (SSP) and $\mathrm{T}_{\mathrm{e}}$. Corresponding to observations (e.g., Zhang and Levitus 1997; Meinen and McPhaden 2000; Kumar and $\mathrm{Hu}$ 2014), the time scale, variability structure and coherent phase relationships among these anomalies are well represented in the ICM. The SST anomalies from this ICM (Fig. 3a) have a reasonable structure and amplitude over the central and eastern equatorial Pacific, with a dominant standing pattern on the equator. While the fluctuations in SST (Fig. 3a) are largest over the central and eastern equatorial Pacific, those 


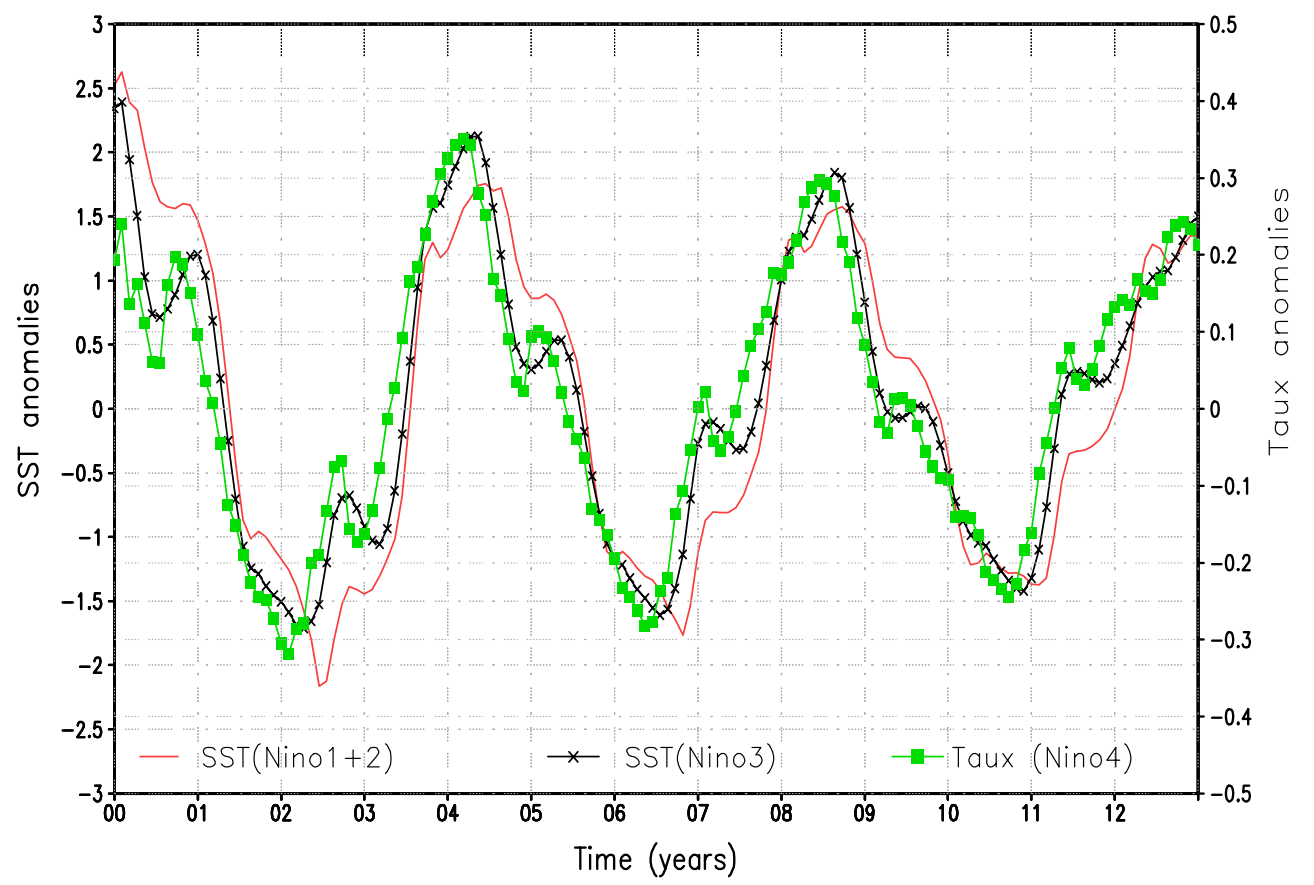

Fig. 2 Time series of the SST anomalies in the Niño1 +2 and Niño3 regions $\left({ }^{\circ} \mathrm{C}\right.$; the scale on the left), and of the zonal wind stress $\left(\tau_{\mathrm{x}}\right)$ anomalies in the Niño4 region $\left(\right.$ dyn $\mathrm{cm}^{-2}$; the scale on the right)

in surface winds (Fig. 3b) are dominantly located over the western and central equatorial regions. At the peak of El Niño events, large warm SST anomalies (approximately $2{ }^{\circ} \mathrm{C}$ ) cover the central and eastern equatorial basin, accompanied by westerly wind anomalies in the west (Fig. 3). One notable feature is that the zonal wind stress anomalies over the western Pacific appear sequentially with two separate signals. For example, one westerly wind anomaly emerges in the far western region in the model in early year 2 (which is limited to the regions only west of $160^{\circ} \mathrm{E}$ ) and persists for a few months (Fig. 3b). Then, another westerly wind anomaly emerges in the midbasin $\left(150^{\circ} \mathrm{E}-170^{\circ} \mathrm{E}\right)$ in early year 3 (Fig. 3b), which is associated with the appearance of a warm SST anomaly near the date line (Fig. 3a). These wind and SST anomalies then amplify rapidly while they propagate eastward along the equator. During the development of El Niño and La Niña events, the zonal wind anomalies, which emerge over the western Pacific, exhibit an eastward migration into the central basin, a feature that is also observed in nature (e.g., Zhang and Levitus 1997). Similar to the SST anomalies, subsurface thermal variations in the ocean, as represented by $\mathrm{T}_{\mathrm{e}}$ (Fig. 4a), exhibit a well-defined pattern of evolution during ENSO cycles, with large variability in the central and eastern equatorial Pacific.

Interannual SSP anomalies display coherent zonal propagation on and off the equator across the basin (Figs. 4b, $5 \mathrm{a}, \mathrm{c})$. It is interesting to note that during the onset and development of ENSO events, SSP variations on the equator indicate two sequentially propagating signals that are of different origins. Using the model's early years 2 and 3 as an example, the first positive SSP anomaly signal originates from the western boundary in early year 2 and then propagates across the equatorial Pacific, arriving at the eastern equatorial Pacific in the middle of year 2 (Fig. 4b). The second positive SSP anomaly signal emerges in the midbasin near $140^{\circ} \mathrm{E}$ in early year 3 (Fig. $4 \mathrm{~b}$ ) and shows eastward propagation along the equator while increasing its amplitude; it arrives at the eastern equatorial region in middle year 3 when large surface warming takes place and develops into an El Niño through late year 3 and early year 4 (Fig. 4a). These SSP anomalies on the equator (Fig. 4b) are closely related to those off the equator (Fig. 5a, c), with coherent zonal propagation serving to carry on the ocean memory around the basin. After the El Niño event in year 0 , for instance, large positive SSP anomalies propagate westward off the equator over the eastern and central Pacific in year 0 (Fig. 5a). In late year 1 and early year 2, the large positive SSP anomalies are seen at $6^{\circ} \mathrm{N}$ over the far western Pacific (Fig. 5c) that can be clearly traced to the eastern basin in year 0 in the off-equatorial regions at $10^{\circ}-15^{\circ} \mathrm{N}$ (Fig. 5a). As there are clear differences in the space-time structure of interannual SSP anomalies at $6^{\circ} \mathrm{N}$ (Fig. 5c) and at $10^{\circ} \mathrm{N}$ (Fig. $5 \mathrm{a}$ ), we chose these latitudinal domains to represent subsurface anomaly characteristics off and on the equator during ENSO evolution. 


\section{Anomalies along the equator}

\section{(a) SST}

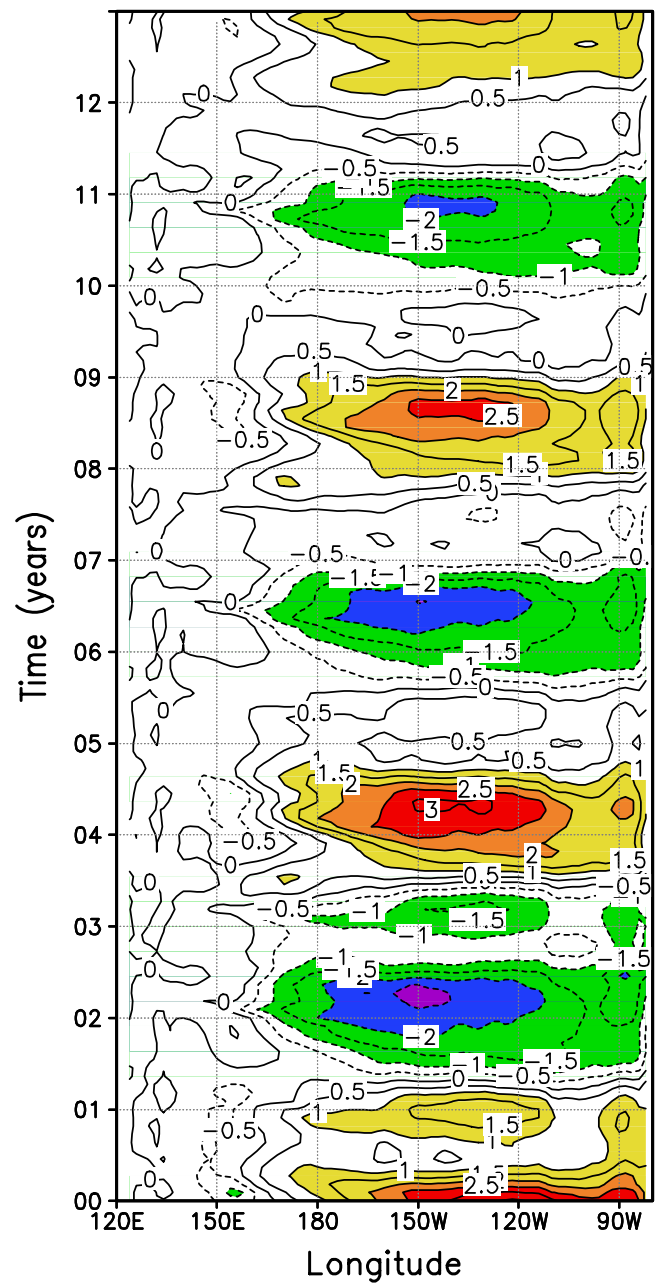

(b) Zonal wind stress

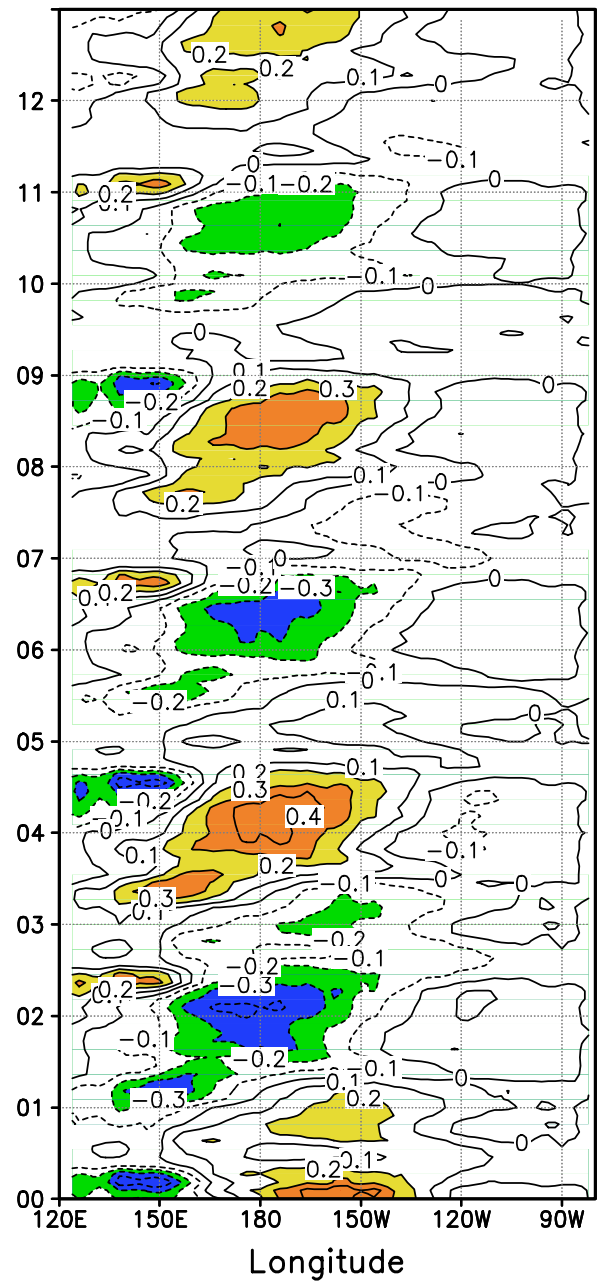

Fig. 3 Longitude-time sections of anomalies for $\mathbf{a}$ SST and $\mathbf{b}$ zonal wind stress along the equator. The contour interval is $0.5{ }^{\circ} \mathrm{C}$ in $\mathbf{a}$ and 0.1 dyn $\mathrm{cm}^{-2}$ in $\mathbf{b}$

Coherent relationships exist between the interannual anomalies of SSP, $T_{e}$ and SST as shown in Fig. 6 for their time series off and on the equator. As examined with Fig. $4 \mathrm{~b}$, the SSP variations exhibit a double peak structure during ENSO cycles. For example, two positive SSP anomaly peaks are seen off the equator at $5^{\circ}-10^{\circ} \mathrm{N}$ over the western-central Pacific in late years 1 and 2 (Fig. 6a); these two peaks correspondingly appear on the equator in early years 2 and 3 (Fig. 6b), with the first peak showing a clear lead-lag relation off and on the equator (an indication of reflections at the western boundary). As the SSP anomalies propagate around the basin, coherent $\mathrm{T}_{\mathrm{e}}$ and SST anomalies emerge. In association with SSP anomalies, $\mathrm{T}_{\mathrm{e}}$ anomalies on the equator (Fig. 4a) propagate eastward in the western Pacific along the equator, and are followed closely by variations in SST, with almost instantaneous phase relations between these two anomaly fields. Off the equator, interannual $\mathrm{T}_{\mathrm{e}}$ anomalies exhibit a slowly varying pattern in the central tropical Pacific (Fig. 6a), with its slightly delayed variation relative to SSP anomalies. Note that the off-equatorial surface warming near the date line in late year 2 and early year 3 (Figs. 5d, 6a) results from the positive offequatorial $\mathrm{T}_{\mathrm{e}}$ anomalies (Figs. 5b, 6a), which are related to the second positive SSP anomaly that appears off the equator in late year 2 (Figs. 5c, 6a). Also note that changes in SST off the equator near the date line closely follow those in $\mathrm{T}_{\mathrm{e}}$ (Fig. 6a), with a slight phase lag of the former relative to the latter, indicating that vertical mixing may take time to transfer the information of the thermocline displacement to temperature anomalies at the sea surface.

To illustrate the space-time evolution in more detail, Figs. 7, 8 and 9 show the snapshots of related anomaly fields 


\section{Anomalies along the equator}

(a) Entrainment temperature

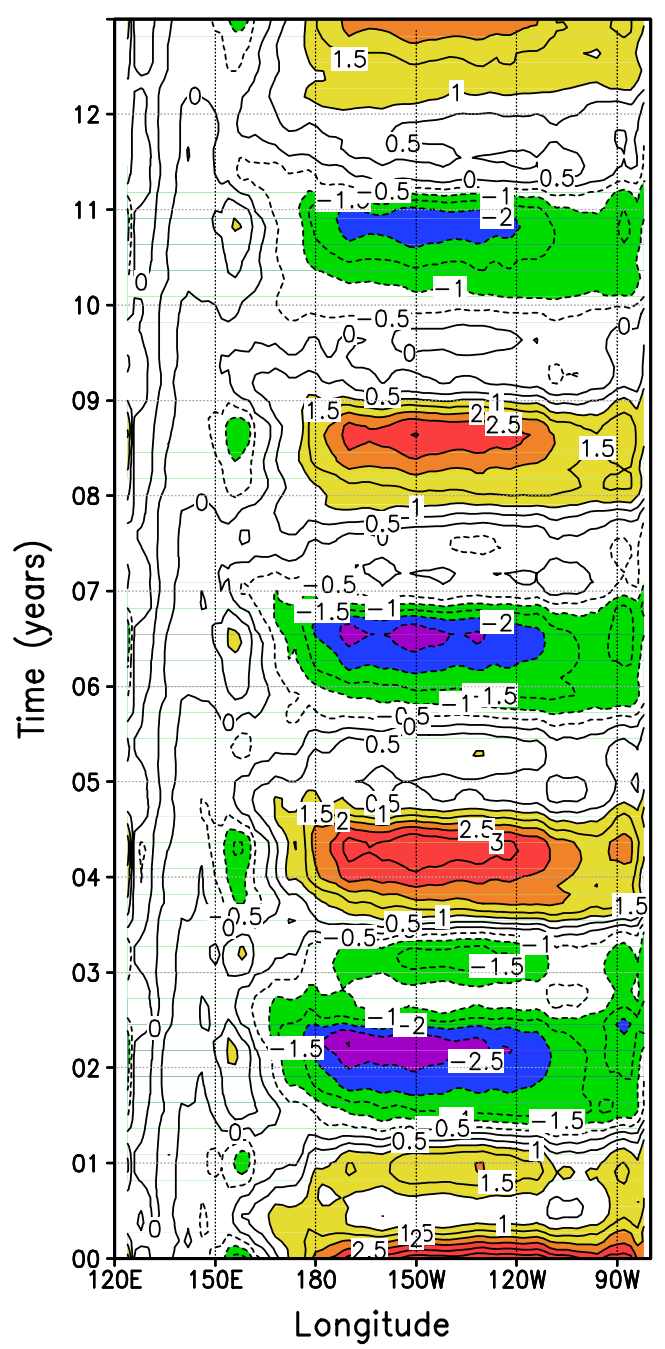

(b) Sea surface pressure

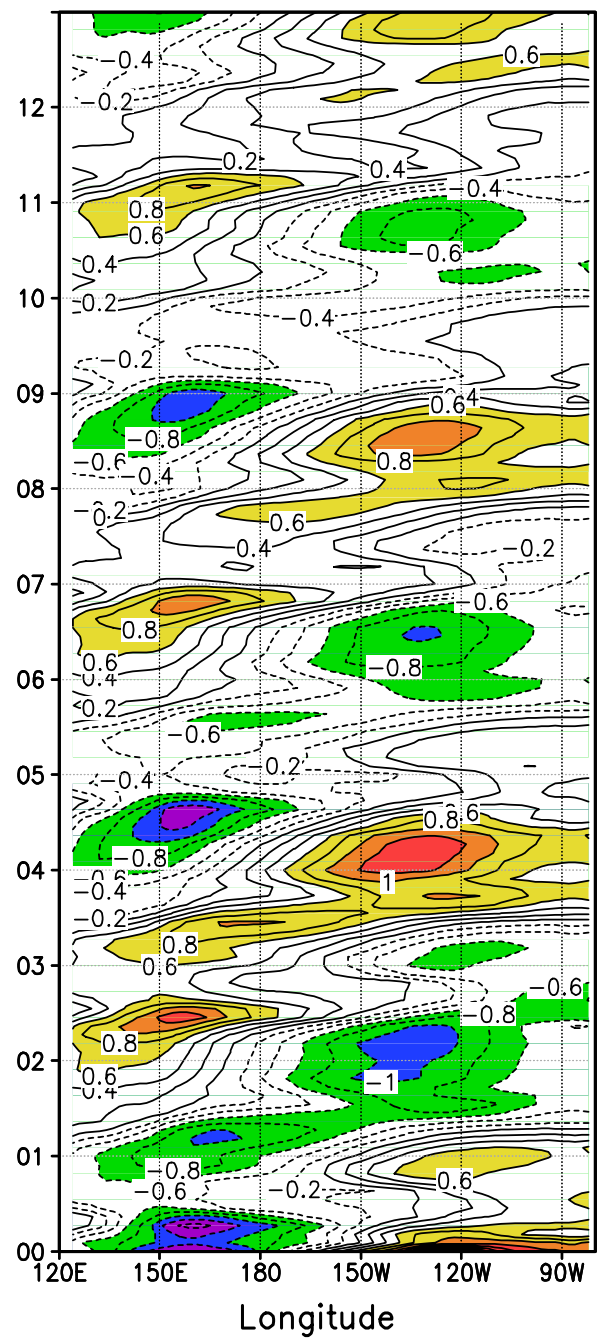

Fig. 4 The same as in Fig. 3 but for $\mathbf{a} \mathrm{T}_{\mathrm{e}}$ and $\mathbf{b}$ sea surface pressure (SSP). The contour interval is $0.5^{\circ} \mathrm{C}$ in $\mathbf{a}$ and $0.1 \mathrm{~cm} \mathrm{~s}^{-2}$ in $\mathbf{b}$

at different periods during El Niño/La Niña transitions. These maps, at 3-month intervals, start with La Niña conditions in year 2, proceed to a transition condition through year 2, and continue to an El Niño condition in years 3 and 4, respectively. Their spatial structure and phase relationships can be more clearly illustrated at the different stages of an ENSO cycle.

In early year 2, La Niña conditions prevail in the tropical Pacific (Fig. 7a). After its peak in early year 2, negative SST anomalies in the east begin to weaken, and the La Niña conditions gradually transition to El Niño conditions, which peak in late year 3 and early year 4 (Fig. 7h, i). The onset of the El Niño event takes place in the tropical Pacific through late year 2 and early year 3 . Starting from model year 2 when the La Niña condition prevails in the eastern basin, the development into the next El Niño in years 3 and 4 involves a slow process of approximately 1-to- 2 years. One pronounced feature during the onset of the El Niño cycle in this ICM simulation is the appearance of a warm SST anomaly off the equator near the date line in middle and late year 2 (Figs. 5d, 7c-e). This warm SST anomaly then extends into the equatorial region near the date line in early year 3 (Fig. 7e, f). Correspondingly, westerly wind anomalies emerge in the midbasin. The changed trade wind may trigger Kelvin wave, which is evident from Figs. 7f, g, to 8f, g. Then, what initiates and sustains the warm SST anomaly near the date line off the equator in late year 2 (Figs. 5d, 7d)?

Looking at subsurface anomalies as represented by SSP, two propagating SSP signals with different origins exhibit sequential and coherent eastward propagation along the equator (Fig. 4b), influencing the SSTs in the equatorial Pacific. One positive SSP anomaly originates near the western boundary in early year 2 (Figs. 4b, 8a), and another positive SSP 


\section{Anomalies at $10 \mathrm{~N}$ and $6 \mathrm{~N}$}

(a) SSP at $10 \mathrm{~N}$

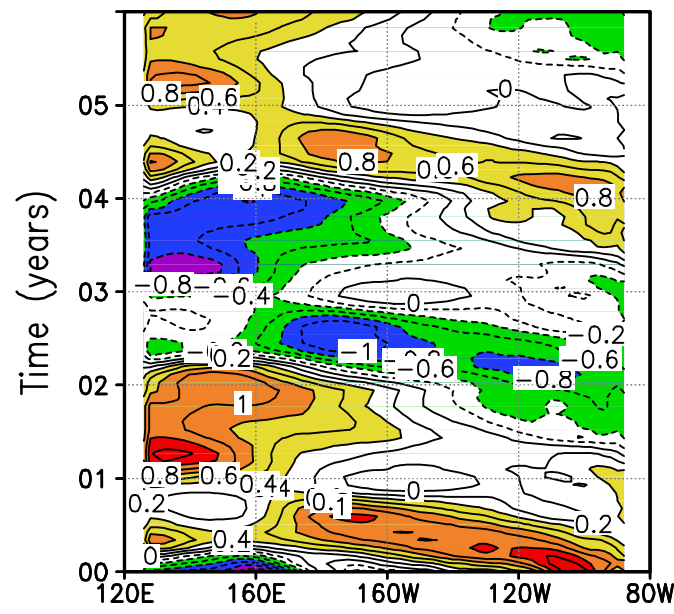

(c) SSP at $6 \mathrm{~N}$

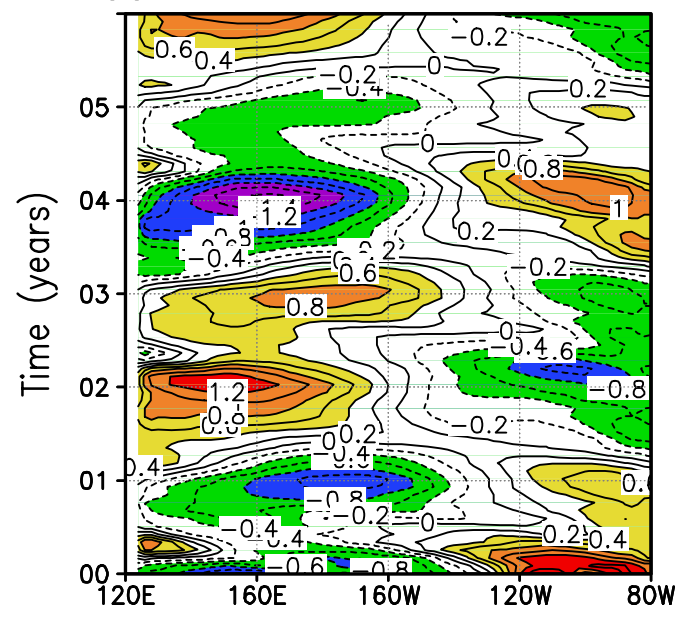

(b) $\mathrm{Te}$ at $10 \mathrm{~N}$

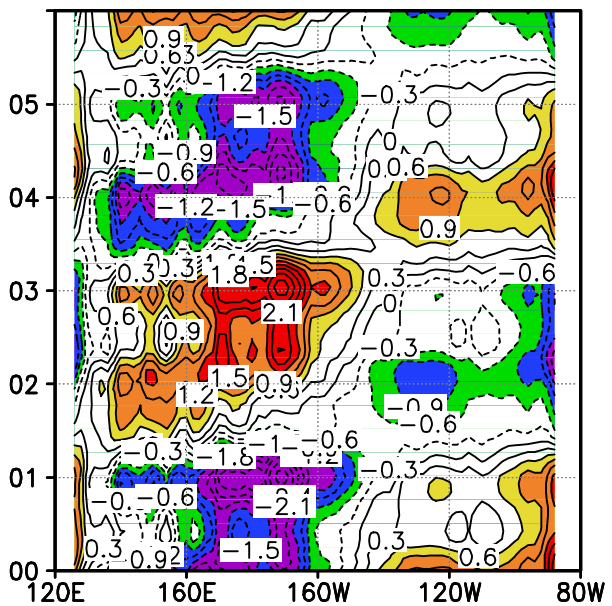

(d) SST at $6 \mathrm{~N}$

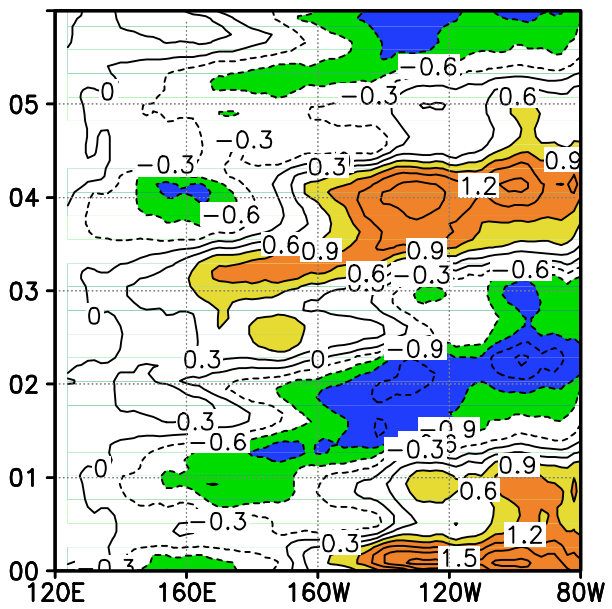

Fig. 5 Longitude-time sections of anomalies for a SSP and $\mathbf{b} \mathrm{T}_{\mathrm{e}}$ along $10^{\circ} \mathrm{N}$ (the upper panels), and for $\mathbf{c}$ SSP and $\mathbf{d}$ SST along $6^{\circ} \mathrm{N}$ (the low panels). The contour interval is $0.2 \mathrm{~cm} \mathrm{~s}^{-2}$ in $\mathbf{a}$ and $\mathbf{c}$, and $0.3{ }^{\circ} \mathrm{C}$ in $\mathbf{b}$ and $\mathbf{d}$

anomaly appears in the midbasin in early year 3 (Figs. 4b, 8e). When the SSP anomalies propagate into the eastern equatorial Pacific, the extent to which they affect $T_{e}$ and SSTs is different. The first SSP signal, being clearly traced to the western boundary as a reflected signal, arrives to the eastern basin in the middle of year 2 but does not trigger an onset of an El Niño event (or it can be said that the effect on the SST is not sufficiently strong to reverse the cold SST anomaly in the east). The second slowly evolving positive SSP anomaly signal is seen along the NECC path (Fig. 8c, e), inducing thermal responses in the western Pacific. Correspondingly, there appears a warm SST anomaly near the date line first off the equator (Figs. $5 \mathrm{~d}, 7 \mathrm{~d}, \mathrm{e}$ ) and then on the equator (Fig. 3a, $7 \mathrm{f}$ ) in late year 2 and early year 3 , which are accompanied by westerly wind anomalies to the west. The induced anomalies of SST and surface winds form ocean-atmosphere coupling off and on the equator, amplifying rapidly as they propagate eastward across the equatorial basin (Fig. $7 \mathrm{~g}-\mathrm{i}$ ). Large warm SST anomalies are seen in the east in late year 3 and early year 4 (Fig. $7 \mathrm{~h}-\mathrm{j}$ ), presenting the onset and development processes of the El Niño event. Thus, the SSP field (Fig. 8) carries an interannual memory in the coupled system, with coherent phase propagation representing the influence of previous winds on the ocean, which is still adjusting. Correspondingly, the thermal response, as manifested by $\mathrm{T}_{\mathrm{e}}$, follows closely with the SSP field, indicating that the dynamic adjustment in the ocean plays an important role in determining $\mathrm{T}_{\mathrm{e}}$ variability over the tropical Pacific.

\subsection{Is El Niño onset directly related to the western boundary reflection?}

To explain El Niño dynamics and its interannual oscillation within the tropical Pacific climate system, the so-called 
Time series

(a) Te, SST \& SSP at $(6 N, 180)$

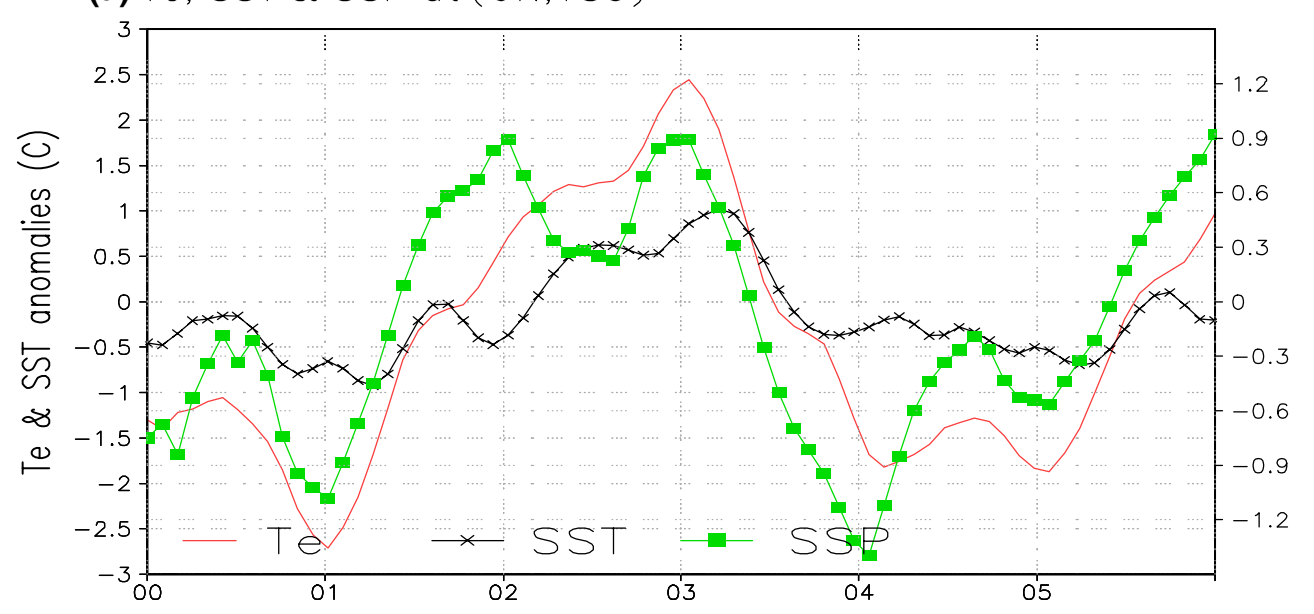

(b) Te, SST \& SSP at (equ., 180)

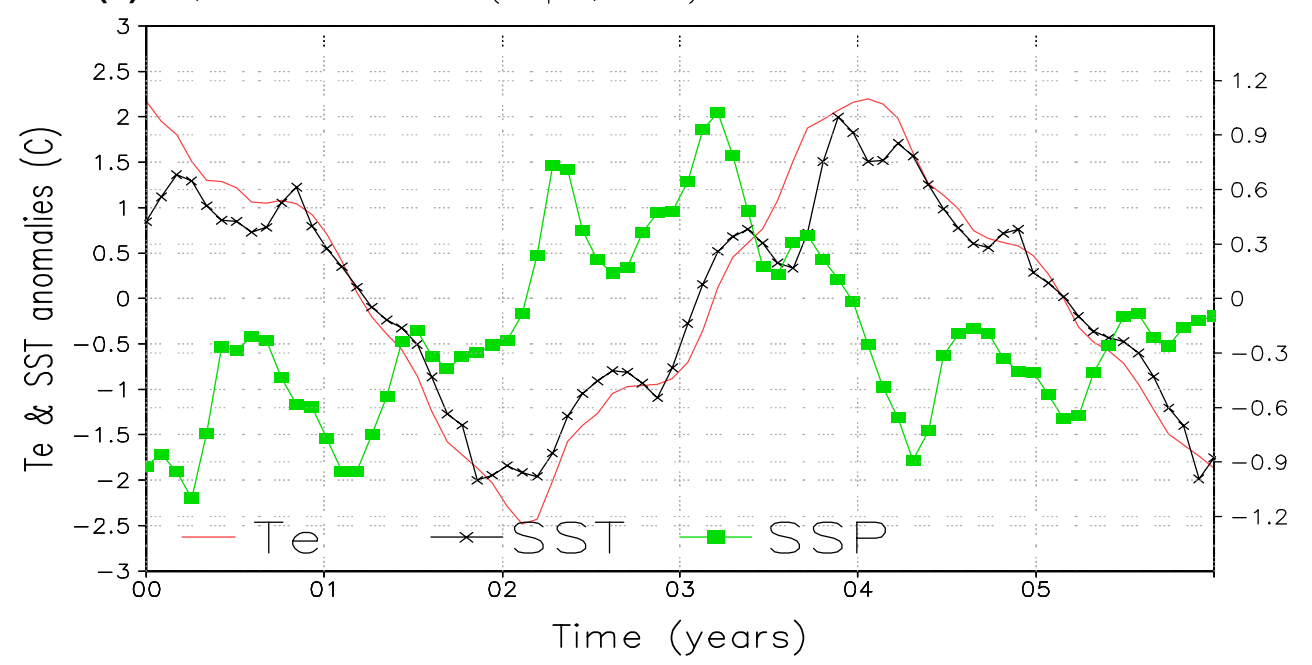

Fig. 6 Time series of $\mathrm{T}_{\mathrm{e}}$, SST and SSP anomalies a at $\left(180^{\circ}, 6^{\circ} \mathrm{N}\right)$ and $\mathbf{b}$ at $\left(180^{\circ}, 0^{\circ}\right)$ from model year 0 to year 5 . The $\mathrm{T}_{\mathrm{e}}$ and $\mathrm{SST}$ scales $\left({ }^{\circ} \mathrm{C}\right)$ are on the left, and the SSP scale $\left(\mathrm{cm} \mathrm{s}^{-2)}\right.$ is on the right

delayed oscillator paradigm has been proposed, serving as a negative feedback for ENSO (Schopf and Suarez 1988; Battisti and Hirst 1989). This theory emphasizes equatorial wave dynamics (the first meridional-mode Rossby wave and its reflection along the low latitude western boundary into a Kelvin wave). The phase reversal in this scenario is realized by an equatorial Rossby wave that is generated midbasin at the peak of El Niño events and propagates westward off the equator towards the western boundary, reflects and returns on the equator as an equatorial Kelvin wave. The slow interannual time scales of observed ENSO evolution (approximately 3-7 years) are attributed to a coupled air-sea instability locally in the midbasin because they cannot be accounted for by these relatively fast equatorial wave processes (i.e., it takes approximately 8 months for an equatorial Rossby wave and approximately 3 months for a
Kelvin wave to propagate across the basin). In this subsection, the relationships between the interannual anomalies of SSP, $T_{e}$ and SST are further analyzed to demonstrate that the direct reflection process is not fundamental to the onset of El Niño events in the ICM.

Following the La Niña event in late year 1 (Fig. 3a), there is a strong downwelling signal off the equator (as Rossby waves) in the western Pacific that propagates westward to the western boundary in late year 1 and early year 2 (Fig. 5c). In early year 2, large positive SSP anomalies are present in the western boundary regions (Fig. 5c), where a positive SSP anomaly originates as a reflected signal (Fig. 4b) and propagates eastward on the equator as equatorial Kelvin waves (Fig. 4b). Its arrival to the east in middle year 2 acts to reduce the cold SST anomalies there, but does not completely reverse the cold conditions. 
(a) Jan year 02

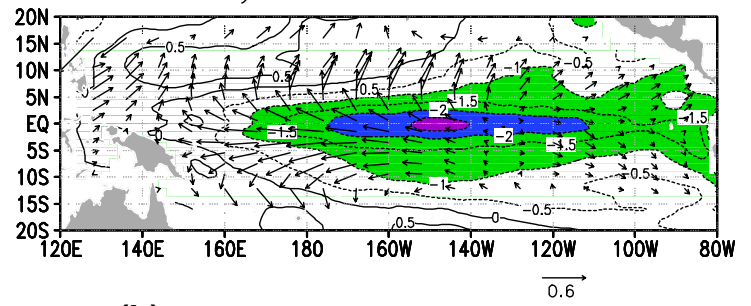

(b) Apr year 02

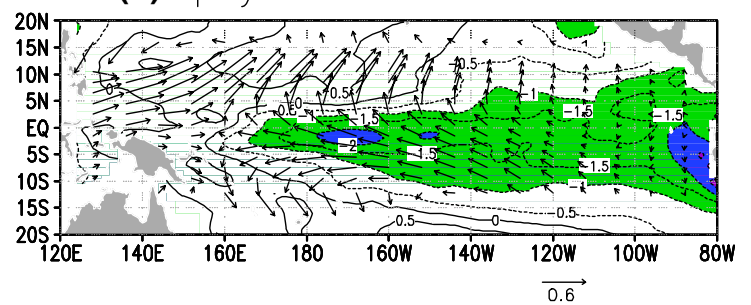

(c) Jul year 02

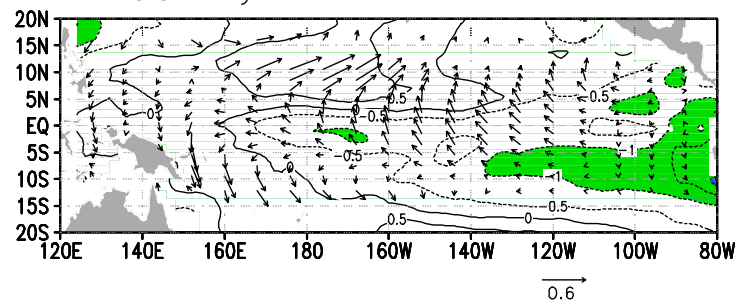

(d) Oct year 02

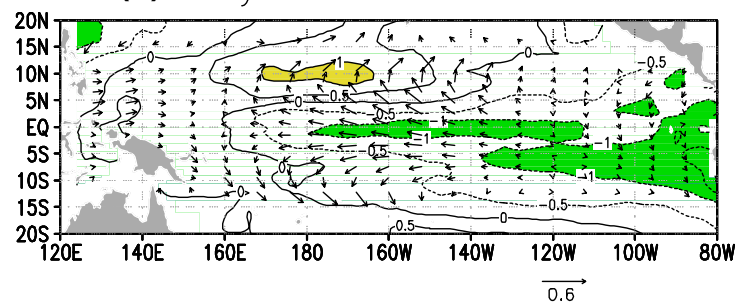

(e) Jan year 03

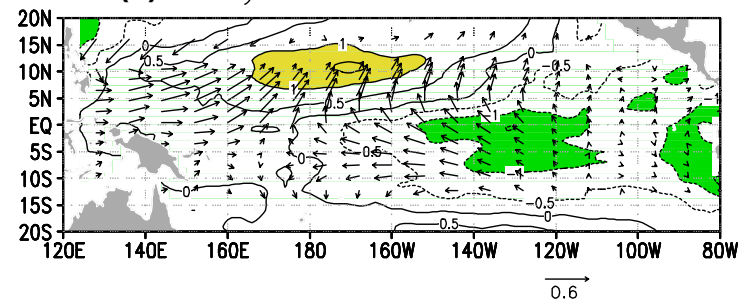

(f) Apr year 03

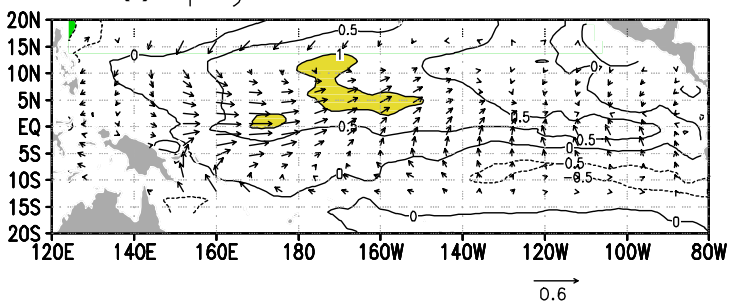

(g) Jul year 03

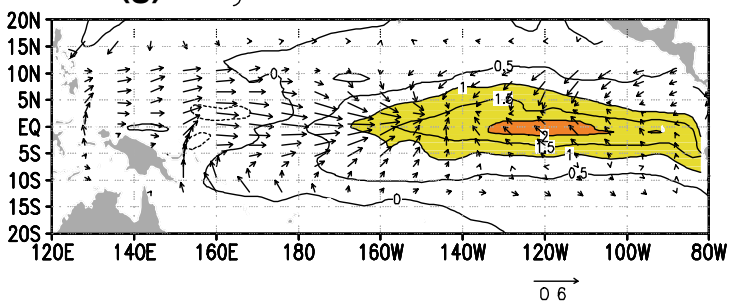

(h) Oct year 03

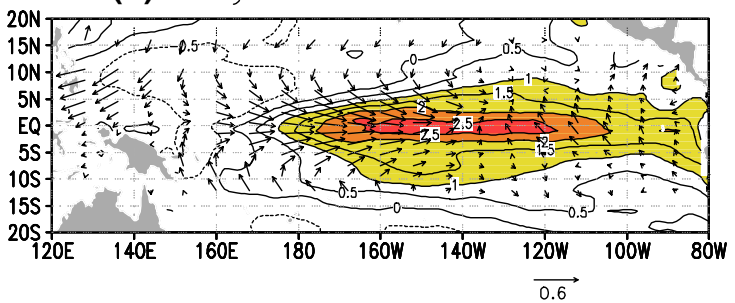

(i) Jan year 04

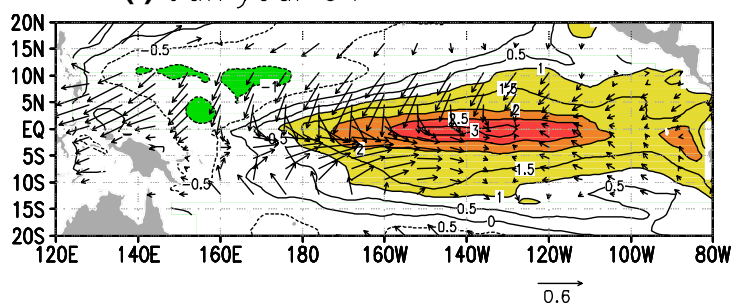

(j) Apr year 04

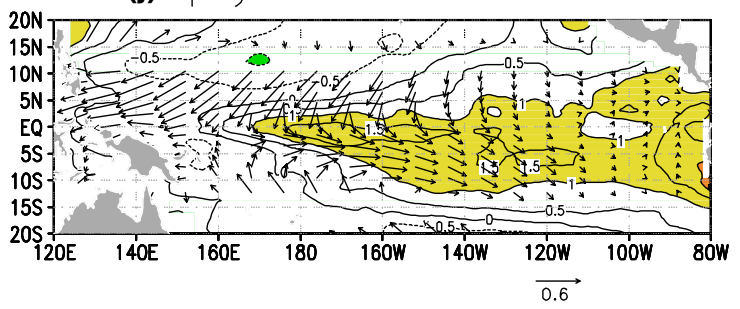

Fig. 7 Horizontal distributions of SST anomalies (contours) and surface wind stress $(\tau)$ anomalies (vectors) during an ENSO cycle from January year 2 to April year 4 . The contour interval is $0.5^{\circ} \mathrm{C}$ for SST

Instead, the actual onset of an El Niño does not occur until late year 3, at a time when there is no explicitly reflected signal from the western boundary. In middle and late year 2 , a striking warm SST anomaly appears first off the equator in the midbasin, accompanied by the occurrence of westerly wind anomalies over the western regions (Fig. 7d, e); by early year 3 , there are noticeable signs of the developing warm event at the sea surface (Fig. 7e, f). Note that the Kelvin waves that trigger the El Niño event in early year 3 (defining the onset of the El Niño in middle year 3) are generated by wind anomalies near the date line that are associated with the first appearance of the warm SST anomalies off the equator (Fig. 5d). Thus, the slow transitional processes from the La Niña to El Niño conditions off and on the equator from year 2 through year 4 cannot be ascribed directly to the reflection processes. In addition to 


\section{$\begin{array}{lll}\text { (a) Jan year } 02 & \text { SSP anomalies } & \text { (f) Apr year } 03\end{array}$}

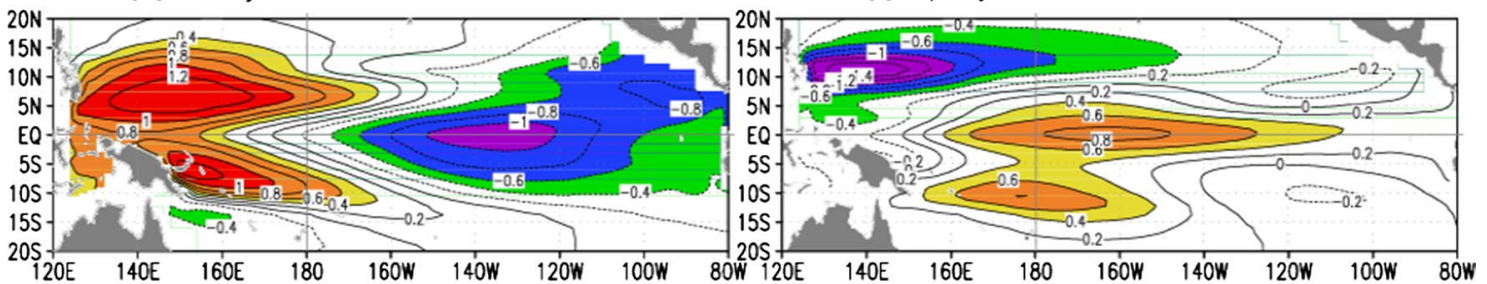

(b) Apr year 02

(g) Jul year 03

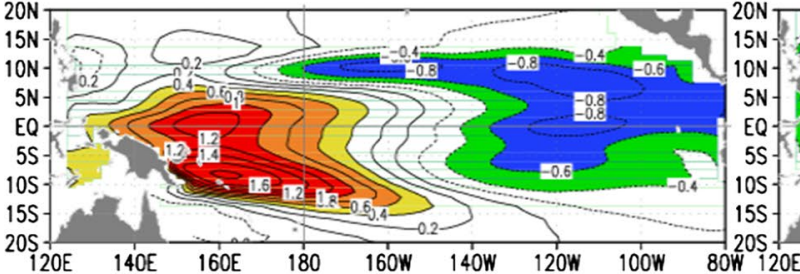

(c) Jul year 02

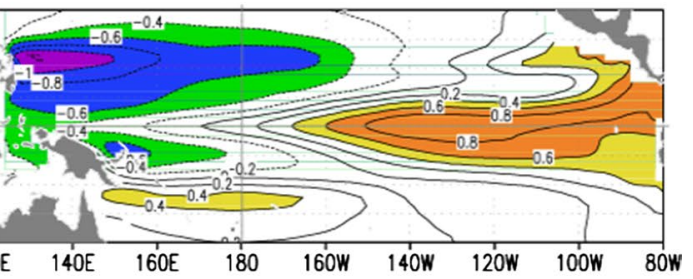

(h) Oct year 03

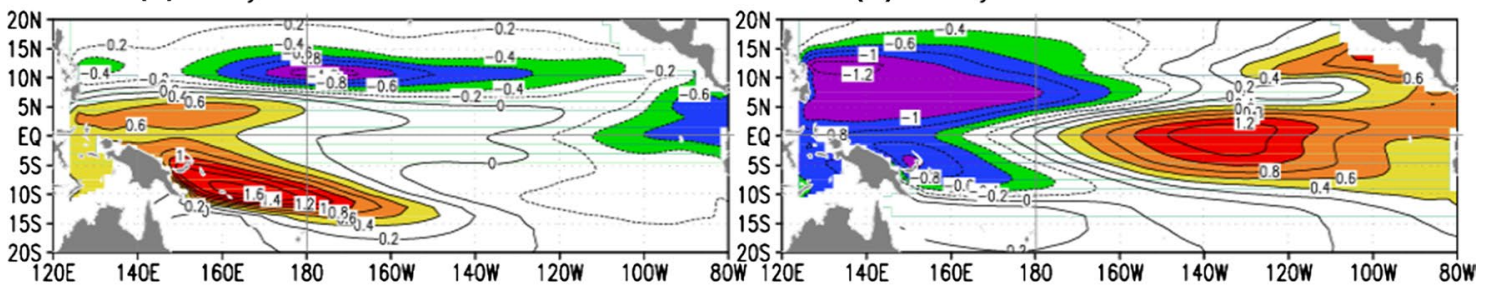

(d) Oct year 02

(i) Jan year 04

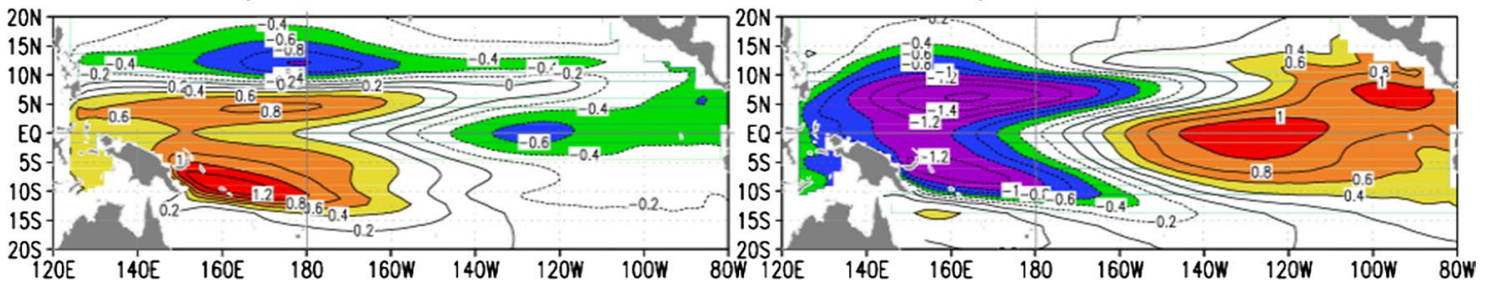

(e) Jan year 03

(j) Apr year 04

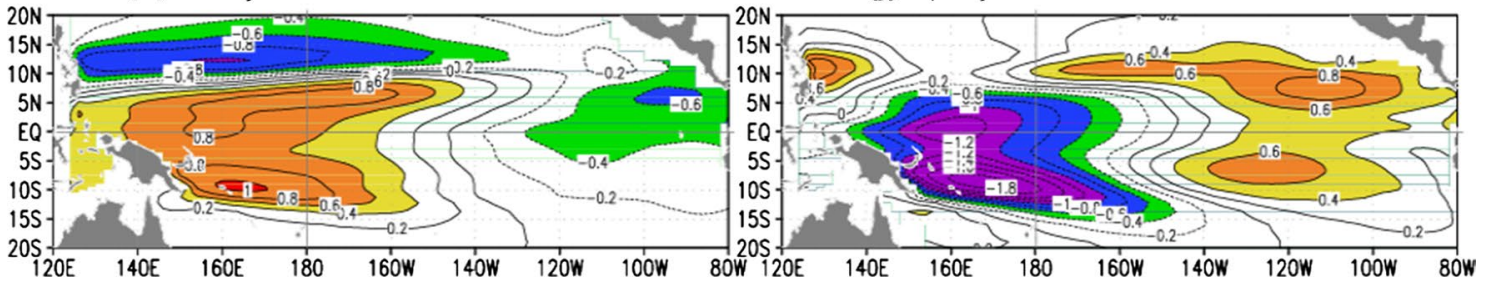

Fig. 8 The same as in Fig. 7 but for SSP anomalies. The contour interval is $0.2 \mathrm{~cm} \mathrm{~s}^{-2}$

the equatorial wave dynamics and reflections at the western boundary as indicated in the delayed oscillator mechanism, other processes must be operating in the system during the onset phase of the warm event in years 2 and 3. These processes need to account for the slow time scales (approximately 1-to-2 years) that are seen to transfer the preconditioned state during the La Niña event off the equator in year 2 to El Niño conditions on the equator in years 3 and 4 . To explain the onset process of the El Niño event in years 2 and 3, additional analyses are highlighted below.

\subsection{The role of off-equatorial $T_{e}$ anomalies during EI Niño cycles}

As presented above, a prominent warm SST anomaly emerges off the equator at $6^{\circ} \mathrm{N}$ in middle to late year 2 (Figs. $5 \mathrm{~d}, 7 \mathrm{c}, \mathrm{d}$ ) and then spreads into the equatorial region near the date line (Fig. 7e, f). As such, the corresponding westerly wind anomalies can be reasonably explained as an atmospheric response to this midbasin warm SST anomaly. These SST and wind anomalies further form air-sea 
(a) Jan year $02 \quad$ Te anomalies

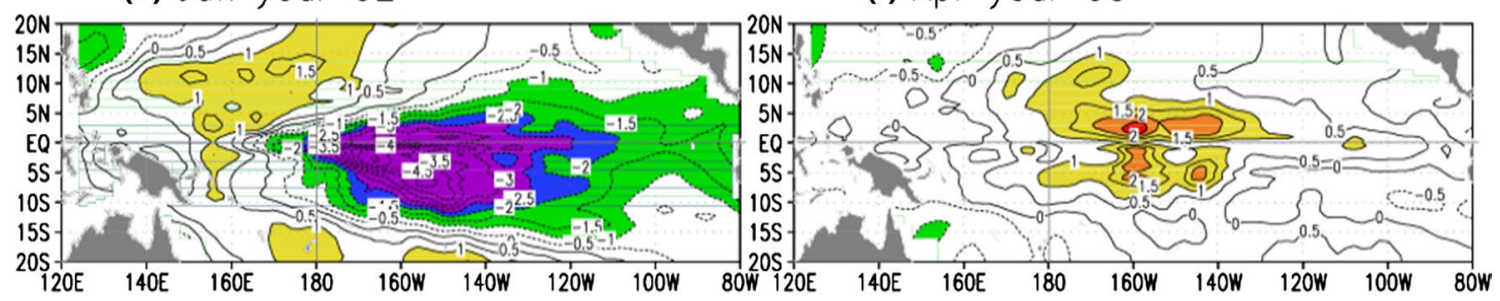

(f) Apr year 03

(b) Apr year 02

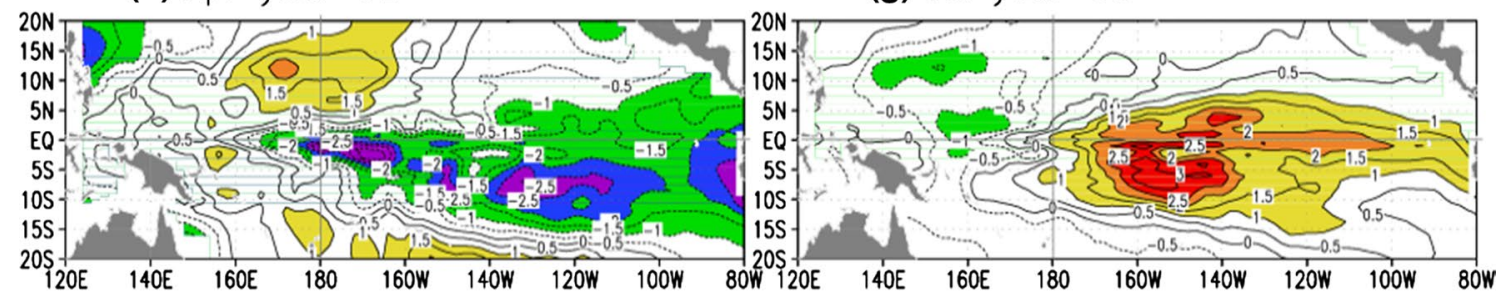

(c) Jul year 02

(h) Oct year 03

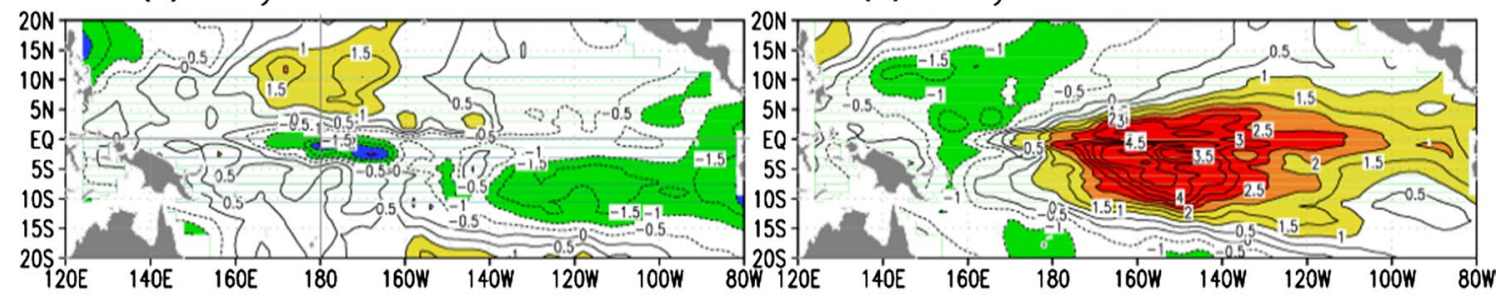

(d) Oct year 02

(i) Jan year 04

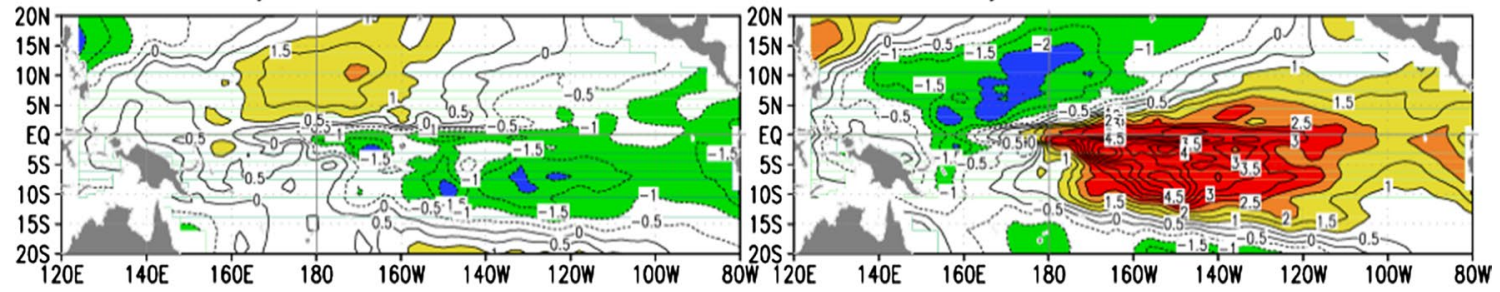

(e) Jan year 03

(j) Apr year 04

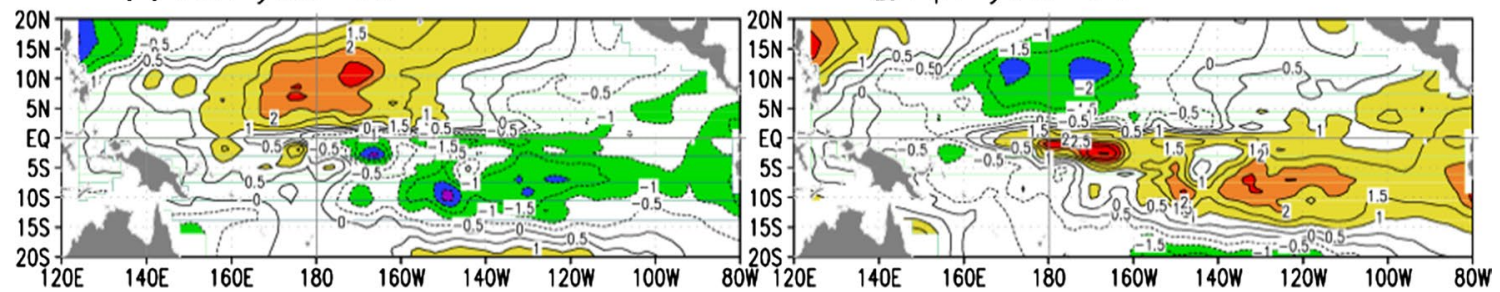

Fig. 9 The same as in Fig. 7 but for $\mathrm{T}_{\mathrm{e}}$ anomalies. The contour interval is $0.5^{\circ} \mathrm{C}$

interactions in the central basin that produce large wind anomalies, leading to the onset of the El Niño event in middle year 3. However, what initiates and sustains the warm SST anomaly near the date line is not known.

As shown in Figs. 3, 4, 5, 6, 7, 8 and 9, a coherent connection can be seen among anomalies of SSP, $\mathrm{T}_{\mathrm{e}}$, SST and surface winds off and on the equator. During the La Niña event in year 2, there is a buildup of warm waters in the western Pacific Ocean due to stronger-than-normal trade winds in the central basin, with the SSP in the west increasing steadily in the 2 years preceding the warm event in years 3 and 4. The subsequent evolution into El Niño takes approximately 2 years. A slowly evolving SSP anomaly pattern is evident along the NECC in the western Pacific (Fig. 8c-e). In particular, the positive SSP anomalies spread eastward and equatorward along the NECC pathways from middle year 2 through early year 3 , which in due course acts to produce $T_{e}$ anomalies (Fig. 9c-e) that can affect 
SST and wind (Fig. 7d-f) off and on the equator near the date line, respectively.

Indeed, the corresponding large $T_{e}$ anomalies emerge off and on the equator in the western Pacific in years 2 and 3 (Fig. 9). In particular, large positive $T_{e}$ anomalies off the equator extend towards the equator in the central basin in early and middle year 2 (Fig. 9c-e), producing a prominent warm SST anomaly that propagates eastward along the NECC path off the equator in mid year 2 (Figs. $5 \mathrm{~d}, 7 \mathrm{c}-\mathrm{e}$ ). This SST anomaly then develops and extends southward into the equatorial regions in the central Pacific (Fig. 7e, f). Additionally, westerly wind anomalies develop over the western and central Pacific (Fig. 7d-f). During the development of the El Niño in middle and late year 3, warm SST anomalies and westerly wind anomalies grow rapidly in the central basin (Fig. 7f), producing large SST anomalies that propagate eastward along the equator (Fig. 3a). The El Niño event occurs at this time.

These results indicate a mechanism by which interannual SST anomalies can be produced along the NECC pathways off the equator in the central basin and can induce westerly wind anomalies over the western tropical Pacific. Thereafter, the resultant SST and wind anomalies develop systematically, amplifying in strength and extending spatially into the equatorial region, triggering the onset of the El Niño. This explanation is different from the delayed oscillator processes in that a major role is played by off-equatorial SSP and $\mathrm{T}_{\mathrm{e}}$ anomalies propagating along the NECC pathway, not necessarily involving the equatorial wave reflections at the western boundary. This analysis illustrates a clear picture of how an El Niño event can be generated in the tropical Pacific climate system.

\section{A heat budget analysis in the mixed layer}

To determine which physical processes are responsible for the interannual SST variability during the El Niño cycle, a heat budget analysis is performed for the mixed layer. The major processes determining the local rate of SST changes (tendency) include horizontal and vertical advection, vertical and horizontal diffusion, and heat flux at the sea surface. Because heat flux always has a damping effect on SST anomalies, it is not shown below.

Figures 10 and 11 illustrate spatial distributions of the budget terms for zonal, meridional and vertical advection, vertical diffusion and their sum at various stages of the simulated El Niño cycle. These figures can be used to illustrate the relative importance of the individual processes affecting SST variability. The contributions of the different terms to the heat budget vary considerably in space and in time during ENSO cycles.
As shown above, one pronounced feature during El Niño cycles in this ICM is the first appearance of a warm SST anomaly off the equator near the date line in middle year 2 (Figs. 5d, 7c, d). This warm SST anomaly then extends equatorward near the date line in late year 2 and early year 3 (Fig. 7d, e). Thus, one key question is how this SST warming is generated off the equator in the coupled system. The heat budget analyses indicate that a positive SST tendency appears near the date line off the equator in late year 2 and early year 3 (e.g., Figure 10a5), which is mainly attributed to the vertical diffusion effect (Fig. 10a4) that is associated with the positive $\mathrm{T}_{\mathrm{e}}$ anomalies (Fig. 9c-e). It is thus clear that through vertical diffusion, the positive $T_{e}$ anomalies induce and sustain the warm SST anomaly off the equator near the date line (Fig. $7 \mathrm{~d}$, e), indicating that warm SST anomalies are initiated by $T_{e}$ variability which is associated with SSP anomalies along the NECC path in the western Pacific (Fig. 8). With time, large SST warming and associated positive vertical diffusion effects are seen in the equatorial regions in spring year 3 (the right panels of Fig. 10).

On the equator, the heat budget at the developing stage of El Niño in year 3 (the left panels of Fig. 11) is dominated by the contribution of zonal advection (Fig. 11a1) in the western and central regions, and by contributions of vertical diffusion, and vertical and meridional advection in the central and eastern region (Figs. 11a2-a4). During the peak of El Niño in early year 4 (e.g., Figure 7i), the heat budget is dominated by contributions of meridional advection and vertical diffusion in the central regions (Fig. 11b2, b4), and by contributions of vertical advection and diffusion in the central and eastern region (Fig. 11b3, b4). In other words, in the central equatorial Pacific, horizontal advection can mainly account for the SST warming (Fig. 11a1) during the development stage, whereas in the eastern equatorial Pacific, vertical advection and diffusion are more important (Fig. 11a4-a4). The further decomposition of various interannual contributions into perturbation temperature fields advected by mean flow and mean temperature fields advected by anomaly currents indicates that anomaly thermal advection by mean currents plays a dominant role in interannual advection anomalies in the western NECC region off the equator, but advection contributions that are associated with mean and anomaly currents are important in both the central and eastern equatorial regions.

Thus, supported by a strong $\mathrm{T}_{\mathrm{e}}$ influence, $\mathrm{SST}$ anomalies are generated and sustained off and on the equator in the tropical Pacific through vertical diffusion. In particular, the positive $T_{e}$ anomalies produce SST warming off the equator along the NECC path in late year 2 and early year 3. On the equator, the positive thermocline feedback (associated with the vertical advection of anomalous $T_{e}$ by the mean upwelling and vertical diffusion) plays an important role in 


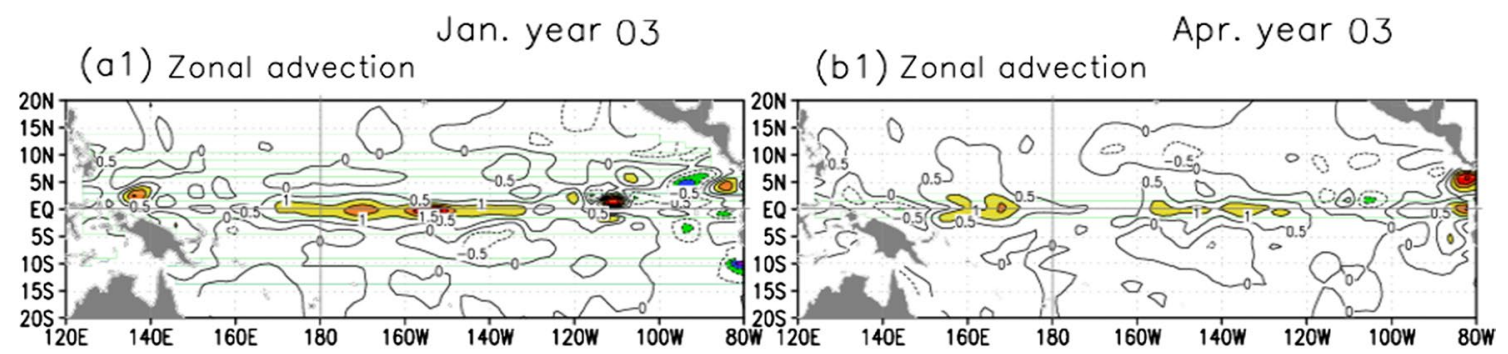

(a2) Meridional advection

(b2) Meridional advection

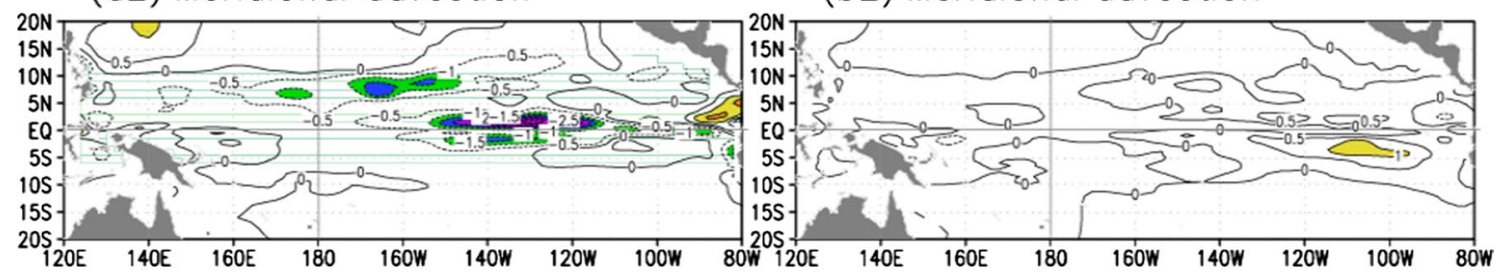

(a3) Vertical advection

(b3) Vertical advection

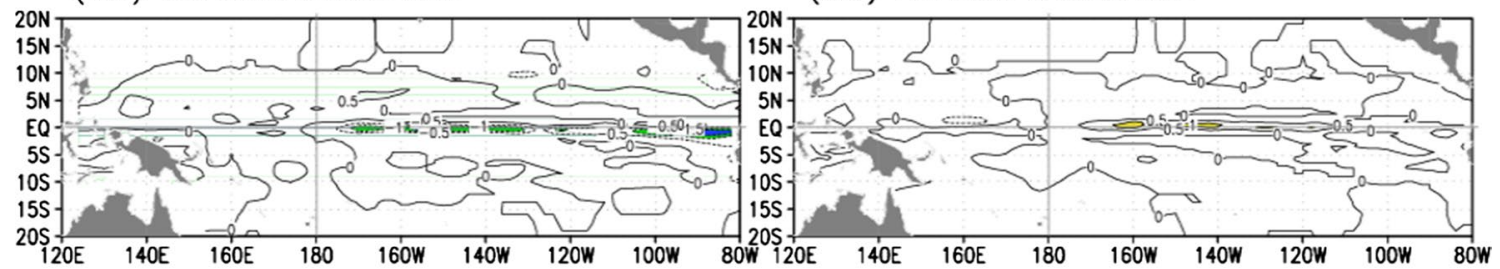

(a4) Vertical diffusion

(b4) Vertical diffusion

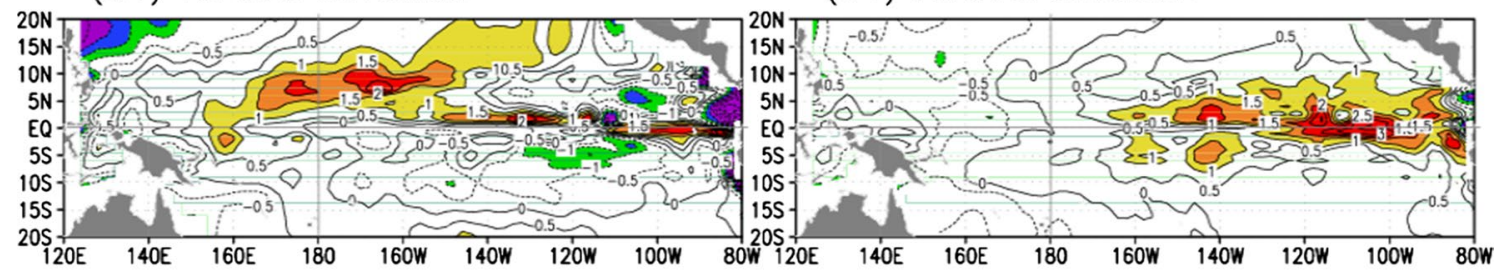

(a5) The above 4-term sum

(b5) The above 4-term sum

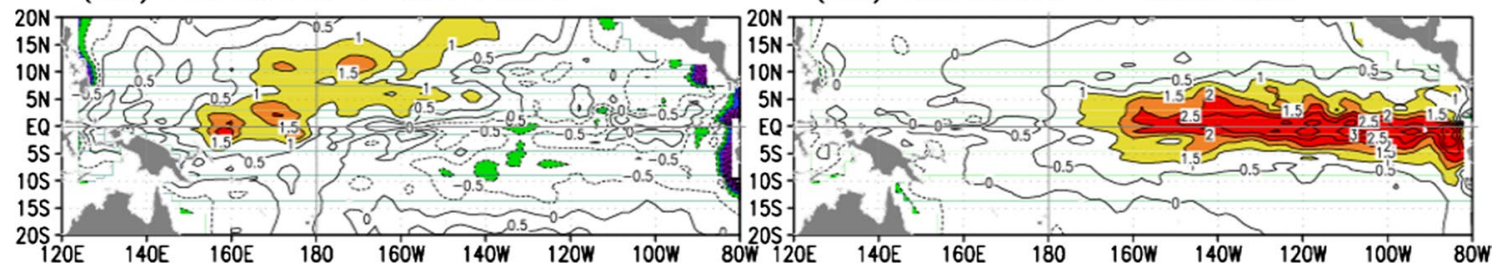

Fig. 10 Horizontal distributions of the budget terms for zonal advection, meridional advection, vertical advection, vertical diffusion, and the sum of these four terms in January of year 3 (left panels) and April of year 3 (right panels). The contour interval is $0.5{ }^{\circ} \mathrm{C}$ month ${ }^{-1}$

the rapid growth of SST and wind anomalies. These results indicate that $\mathrm{T}_{\mathrm{e}}$ plays a dominant role in controlling SST variability in the tropical Pacific. Through the entrainment process, a dynamic adjustment can exert direct and immediate influences on SST over the central and eastern equatorial basin.

Note that there have been a lot works examining the heat budget in the mixed layer associated with ENSO evolution in ocean reanalyses or model simulations (e.g., Huang et al. 2010). The results obtained from this work are consistent with these analyses and modeling studies, indicating the dominant role played by subsurface processes in SST evolution of the tropical Pacific.

\section{Conclusion and discussion}

In this study, an analysis is presented to determine the processes that are responsible for the onset of El Niño events based on a simulation of an intermediate coupled model (ICM) consisting of an intermediate ocean model $(\mathrm{IOM})$ and a statistical atmospheric wind stress model of 
Oct. year 03 (a1) Zonal advection

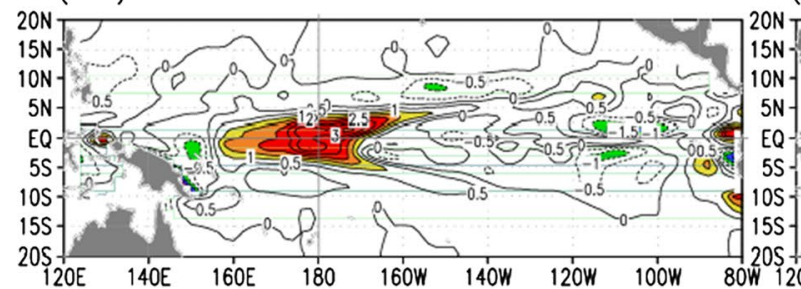

(a2) Meridional advection

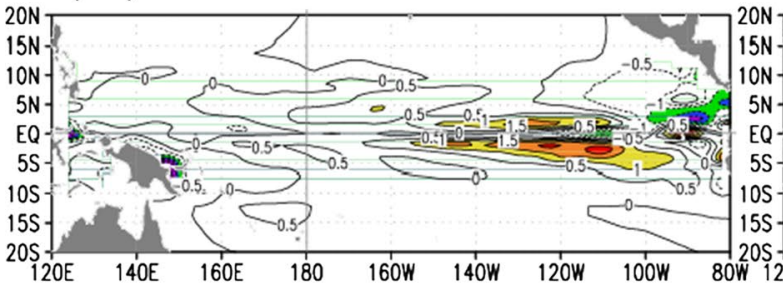

(a3) Vertical advection

Jan. year 04

(b1) Zonal advection

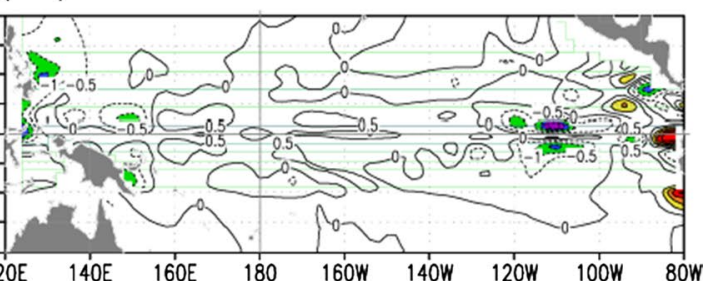

(b2) Meridional advection

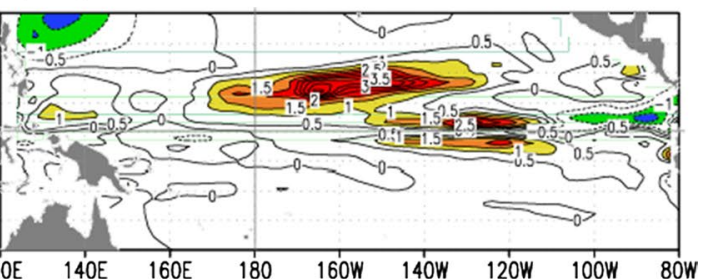

(b3) Vertical advection

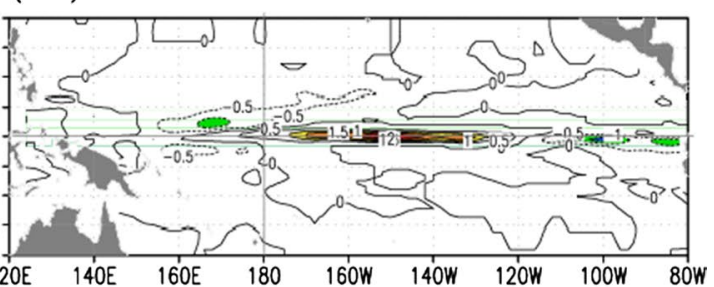

(b4) Vertical diffusion

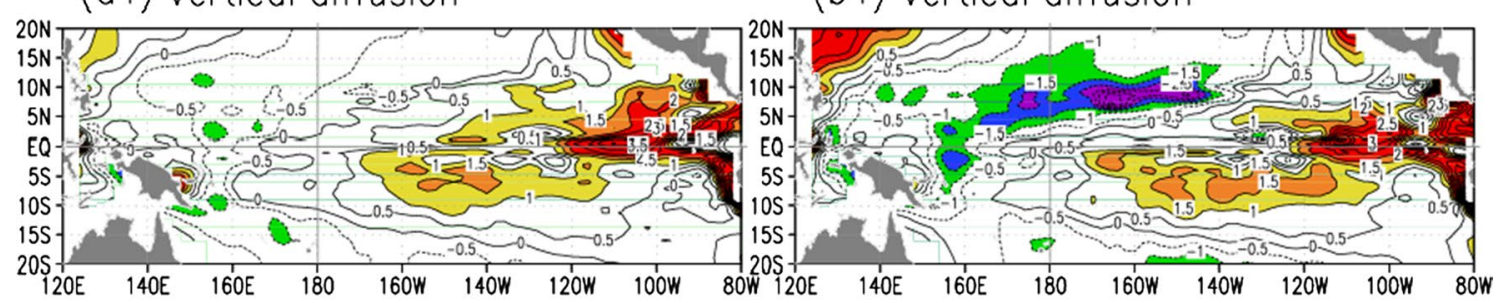

(a5) The above 4-term sum

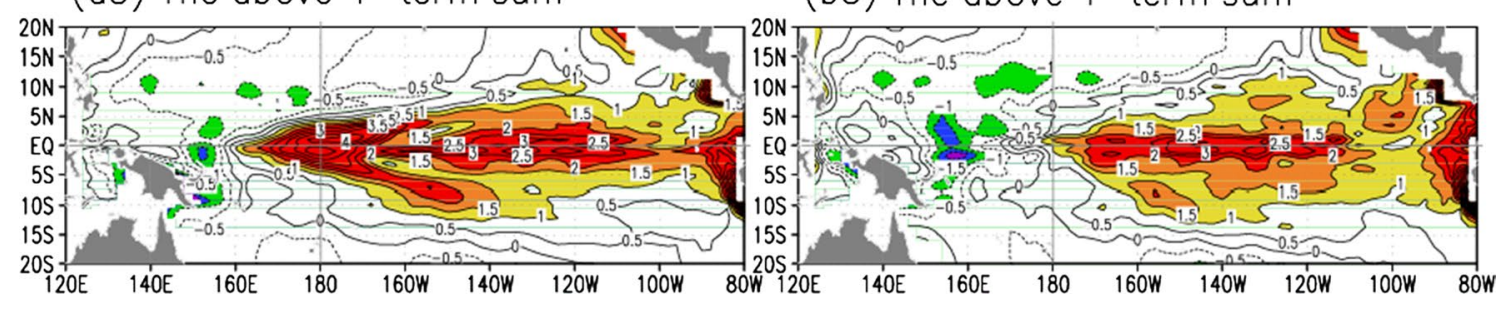

Fig. 11 The same as in Fig. 10 but for October of year 3 (left panels) and January of year 4 (right panels)

the tropical Pacific. One crucial component of this ICM is the determination of the temperature of the subsurface water entrained into the surface mixed layer $\left(T_{e}\right)$. A novel approach is developed to optimize $\mathrm{T}_{\mathrm{e}}$ using an inverse modeling of an SST anomaly equation. The ICM, as optimized, can realistically simulate interannual SST variability in the tropical equatorial Pacific because the improved $\mathrm{T}_{\mathrm{e}}$ calculation adequately represents the subsurface effect on SST variability due to the vertical advection and diffusion terms.
In particular, the ICM can depict ENSO cycles well, with an approximately 4-year oscillation period. The spatial structure and temporal evolution of some related anomaly fields are analyzed to illustrate how an El Niño event can be generated in the tropical Pacific. One striking feature during the onset of El Niño events is the appearance of a warm SST anomaly along the NECC near the date line.

The SSP field serves as an interannual memory in the coupled system, with coherent phase propagation off and 
on the equator during El Niño evolution. For example, two propagating positive SSP anomaly signals with different origin are evident on the equator during the transition from the La Niña conditions in year 2 to the El Niño conditions in year 3. One originates as a reflected signal directly from the western boundary regions in association with La Niña in year 2. When this signal arrives to the eastern equatorial Pacific in middle year 2, the resultant effect is not strong enough to completely reverse the sign of the cold SST anomalies in the eastern equatorial Pacific. The second positive SSP anomaly signal originates in the middle basin west of the date line in early year 3 . When this signal arrives to the eastern equatorial Pacific in middle year 3 , it leads to a large surface warming and the onset and development of an El Niño event in middle and late year 3. Since there is no reflected signal directly from the western boundary at this time, the onset of the El Niño event cannot be ascribed to reflection processes as indicated by the delayed oscillator mechanism. Additionally, the transition from the La Niña in year 2 into the El Niño in late year 3 takes approximately 1-to-2 years, a time scale that cannot be accounted for by equatorial wave processes. Other mechanisms are needed to trigger the onset of El Niño event in early year 3 . The key is to explain the initial SST warming along the NECC path in the central basin.

A detailed examination indicates that the second propagating SSP anomaly signal (which originates from the midbasin) involves a slow process along the NECC path in years 2 and 3. During La Niña in year 2, the accumulation of warm waters causes large positive SSP anomalies in the western Pacific that tend to spread as a slowly evolving signal along the NECC pathways, with the expected mean circulation in the western Pacific. In particular, the positive SSP anomaly progresses coherently eastward and then southward towards the equator in the central basin in year 2 through year 3 . In early year 3 , a very large positive SSP anomaly is seen on the equator near the date line that is not associated with the western boundary reflections of the downwelling Rossby waves that are produced during the La Niña in year 2.

Furthermore, these propagating SSP anomalies influence the thermal conditions around the basin, with their coherent relationships with $T_{e}$ and SST off and on the equator near the date line. Indeed, the subsurface thermal response (as manifested by $\mathrm{T}_{\mathrm{e}}$ ) follows closely with the propagating SSP anomalies, with a well-defined $\mathrm{T}_{\mathrm{e}}$ pattern exhibiting a slowly evolving anomaly signal along the NECC path in middle year 2 through early year 3 . In particular, a positive $T_{e}$ anomaly emerges off the equator in middle year 2 , generating and sustaining a warm SST anomaly first off the equator and then on the equator in the western Pacific. When the warm SST anomaly is produced in the central basin, the development of the westerly wind anomaly can be reasonably explained as a response to it. The SST and wind anomalies that are produced can then locally initiate air-sea interactions in the western Pacific, producing large wind anomalies in the midbasin that produce Kelvin waves triggering the onset of the El Niño event in year 3 .

Thus, slowly evolving $T_{e}$ anomalies generate a warm SST anomaly off and on the equator along the NECC pathways in the western tropical Pacific that further induces surface wind anomalies. Indeed, the time that is needed for a subsurface anomaly to extend along the NECC pathway to the date line (approximately one year) is consistent with the timing that is involved in the onset phase of the El Niño event. Budget analyses indicate that through vertical diffusion effect, this $\mathrm{T}_{\mathrm{e}}$ anomaly initiates the warm SST anomaly in middle year 2 and early year 3. Subsequently, these resultant SST and wind anomalies form "coupled interactions" that result in a large-scale relaxation of the trade winds over the western and central equatorial basin, generating eastward currents that transport water mass eastward along the equator, triggering the onset of the El Niño in middle year 3.

The suggested transition mechanism for the onset of El Niño events, ascribing to off-equatorial subsurface anomalies propagating along the NECC pathway, is clearly different from that of the delayed oscillator processes. New to this ICM-based study is the suggestion of a prominent role of off-equatorial $\mathrm{T}_{\mathrm{e}}$ anomalies evolving in the western tropical Pacific in initiating a warm SST anomaly off and on the equator near the date line. Note that we here only analyze one El Niño simulation in model years 3-4 to discuss this new transition mechanism. To make our results and arguments more convincing, we also look at the other El Niño events produced in the ICM, say in year 8 and year 12 of the simulation. Similar space-time evolution of the related anomaly fields (e.g., SSP, $\mathrm{T}_{\mathrm{e}}$ and SST) and their interrelationships are seen. So, the results described in this paper are robust and the same transition mechanism is at work during the onsets of all El Niño events in the model.

The observed 1991-1992 El Niño event is one of good examples fitting the processes discussed in this modeling work. As detailed by Kessler and McPhaden (1995) and Zhang and Rothstein (2000), processes described from the ICM simulation are consistent with the onset and development of the 1991-1992 El Niño event. During the strong La Niña event in 1988-1989, there was a buildup of heat in the western tropical Pacific Ocean for more than a year due to stronger-than-normal trade winds, preconditioning the onset and development of an El Niño event in 1991-1992. In late 1990 and early 1991, there were large warm subsurface temperature anomalies along the western boundary; at this time, however, cold conditions still prevailed in the central and eastern equatorial Pacific. Starting in approximately late 1990 and early 1991, the subsurface anomalies extended eastward over approximately one year off and on the equator 
along the NECC path, initiating a warm SST anomaly off the equator near the date line that then moved southward onto the equator due to the convergence of mean ocean flow. As the warm SST anomaly was formed off the equator near the date line in late 1990 and early 1991, westerly wind anomalies occurred over the western tropical Pacific that can be reasonably interpreted as an atmospheric response to the warm SST anomalies. Subsequently, the resultant anomalies in the atmosphere and in the ocean induced coupled interactions over the western and central equatorial Pacific, resulting in a large-scale relaxation of the trade winds that triggered a downwelling Kelvin wave propagating along the equator, driving eastward currents that transported water mass from the west to east along the equator, thus triggering the onset of an El Niño in 1992. Note that during the El Nino onset time, there was no obvious reflected signal from the western boundary (Kessler and McPhaden 1995), indicating that the origin of the El Niño event could not be directly ascribed to the reflection processes. Instead, offequatorial $\mathrm{T}_{\mathrm{e}}$ anomalies played an important role in generating and sustaining the warm SST anomaly near the date line in middle 1991, inducing westerly wind anomalies and Kelvin waves propagating eastward along the equator, setting up the onset stage for the 1991-1992 El Niño event.

The mechanism for the roles of reflected signals at the western boundary and off-equatorial anomalies seen in this modeling work is consistent in some extent with the so-called western Pacific Oscillator theory (Weisberg and Wang 1997). In the atmosphere, condensation heating in the western and central Pacific was induced by twin offequatorial cyclones and westerly wind anomalies at the equator. In the ocean, the anomalous wind stress deepens the thermocline and increases the SST in the eastern equatorial Pacific. Positive feedback between wind stress and SST leads to growth of El Niño. Meanwhile, the pair of cyclones raises the thermocline in the far western Pacific, so that SST decreases and sea level pressure increases off the equator in the west. Anomalous high pressure induces easterly wind anomalies which cause upwelling and cooling. The cooling spreads eastwards along the equator and provides a negative feedback onto the warming in the east, thereby creating an oscillating coupled ocean-atmospheric system. Unlike the delayed oscillator theory, this mechanism does not require wave reflection at the western boundary for the coupled ocean-atmosphere system to oscillate. Also, inspection from Fig. 7 indicates that there is the possibility that the off-equatorial thermal anomaly may affect the trade wind along the equator by the so-called footprinting mechanism associated with subsurface heating effect (Alexander et al. 2010). Further detailed analyses are needed to address the role of this process in the ENSO evolution simulated in the ICM. In addition, as clearly evident from Fig. 3, ENSO simulations in the ICM are much more regular in both spatial pattern and temporal evolution than in the observations. This is a comment default of the current ICM, and even for some coupled general circulation model simulations. As seen above, ENSO simulated in the ICM with reasonable model parameters is self-maintained and doesn't need extra forcing from the atmosphere, whereas in reality, ENSO is affected (sometime triggered) by atmospheric disturbances and thus becomes pronouncedly irregular in its space-time evolution. In this work, a statistically constructed wind stress model from historical data is used to represent signal part of interannual wind variability responding to SST anomalies, with stochastic wind forcing part being excluded. That may be one of the reasons resulting in the too regular ENSO in the ICM. Our previous modeling work using the ICM indeed indicated that inclusion of stochastic wind forcing effect leads to an irregular oscillation (Zhang et al. 2008). Here, we identify a deterministic process that can give rise to wind variability in the western tropical Pacific responding to SST anomalies which are generated by off-equatorial thermal anomalies along the NECC regions. The roles of these wind forcings (stochastic vs. deterministic) in observed El Niño onset and evolution need to be addressed in the future.

Acknowledgments We would like to thank Dr. A. J. Busalacchi for his comments, and P. Chang for his help in constructing the SVDbased statistical model. The author wishes to thank the two anonymous reviewers for their numerous comments that helped to improve the original manuscript. This research is supported by IOCAS through the CAS Strategic Priority Project (the Western Pacific Ocean System (WPOS); (XDA11010301)), the National Basic Research Program (973 program) of China (Grant No. 2012CB956000), the National Natural Science Foundation of China (Grant No. 41475101), the NSFC-Shandong Joint Fund for Marine Science Research Centers (Grant No. U1406401), and the NSFC Innovative Group Grant (Project No. 41421005).

Open Access This article is distributed under the terms of the Creative Commons Attribution 4.0 International License (http://creativecommons.org/licenses/by/4.0/), which permits unrestricted use, distribution, and reproduction in any medium, provided you give appropriate credit to the original author(s) and the source, provide a link to the Creative Commons license, and indicate if changes were made.

\section{References}

Alexander MA, Vimont DJ, Chang P, Scott JD (2010) The Impact of extratropical atmospheric variability on ENSO: testing the seasonal footprinting mechanism using coupled model experiments. J Clim 23:2885-2901. doi:10.1175/2010JCLI3205.1

Barnett TP, Latif M, Graham N, Flugel M, Pazan S, White W (1993) ENSO and ENSO-related predictability. Part I: prediction of equatorial Pacific sea surface temperature with a hybrid coupled ocean-atmosphere model. J Clim 6:1545-1566

Battisti DS, Hirst AC (1989) Interannual variability in the tropical atmosphere-ocean system: influences of the basic state, ocean geometry and nonlinearity. J Atmos Sci 46:1687-1712 
Bjerknes J (1969) Atmospheric teleconnections from the equatorial Pacific. Mon Weather Rev 97:163-172

Cane MA, Zebiak SE (1985) A theory for El Niño and Southern Oscillation. Science 228:1084-1087

Chang P, Ji L, Saravanan R (2001) A hybrid coupled model study of tropical Atlantic variability. J Clim 14:361-390

DeWitte B, Gushchina D, duPenhoat Y, Lakeev S (2002) On the importance of subsurface variability for ENSO simulation and prediction with intermediate coupled models of the tropical Pacific: a case study for the 1997-1998 El Niño. Geophys Res Lett. doi:10.1029/2001GL014452

Huang B, Xue Y, Zhang D, Kumar A, McPhaden MJ (2010) The NCEP GODAS ocean analysis of the tropical Pacific mixed layer heat budget on seasonal to interannual time scales. J Clim 23:4901-4925

Ji M, Behringer DW, Leetmaa A (1998) An improved coupled model for ENSO prediction and implications for ocean initialization, Part II: the coupled model. Mon Weather Rev 126:1022-1034

Jin F-F, An S-I (1999) Thermocline and zonal adjective feedbacks within the equatorial ocean recharge oscillator model for ENSO. Geophys Res Lett 26:2989-2992

Kalnay E et al (1996) The NMC/NCAR reanalysis project. Bull Am Met Soc 77:437-471

Keenlyside N, Kleeman R (2002) On the annual cycle of the zonal currents in the equatorial Pacific. J Geophys Res. doi:10.1029/2 000JC0007111

Kessler WS, McPhaden MJ (1995) Oceanic equatorial waves and the 1991-93 ElNino. J Clim 8:1757-1774

Kleeman R (1993) On the dependence of hindcast skill on ocean thermodynamics in a coupled ocean-atmosphere model. J Clim 6:2012-2033

Kumar A, Hu Z-Z (2014) Interannual and interdecadal variability of ocean temperature along the equatorial Pacific in conjunction with ENSO. Clim Dyn 42:1243-1258. doi:10.1007/ s00382-013-1721-0

Large WG, Gent PR (1999) Validation of vertical mixing in an equatorial ocean model using large eddy simulations and observations. J Phys Oceanogr 29:449-464

Latif M, Sperber K et al (2001) ENSIP: the El Niño simulation intercomparison project. Clim Dyn 18:255-276

Levitus S (1982) Climatological atlas of the World Ocean. NOAA Prof. Pap. 13, 173 pp, U.S. Govt. Print. Off., Washington, DC

McCreary JP (1981) A linear stratified ocean model of the equatorial undercurrent. Philos Trans R Soc Lond 298:603-635

McCreary JP, Anderson DLT (1991) An overview of coupled oceanatmosphere models of El Nino nad the Southern Oscillation. J Geophys Res 96:3125-3150

Meinen CS, McPhaden MJ (2000) Observations of warm water volume changes in the equatorial Pacific and their relationship to El Niño and La Niña. J Clim 13:3551-3559

Neelin JD, Jin F-F (1993) Modes of interannual tropical ocean-atmosphere interaction a united view, Part II: analytical results in the weak-coupling limit. J Atmos Sci 50:3504-3522

Neelin JD et al (1992) Tropical air-sea interactions in general circulation model. Clim Dyn 7:73-104

Reynolds RW, Smith TM (1994) Improved global sea surface temperature analysis using optimum interpolation. J Clim 7:929-948

Schopf and Suarez (1988) Vacillations in a coupled ocean-atmosphere model. J Atmos Sci 45:549-566
Stockdale T, Anderson D, Davey M, Delecluse P, Kattenberg A, Kitamura Y, Latif M, Yamagata T (1993) Intercomparison of tropical ocean GCMs. WRCP-79, WMO/TD-no. 545, 43 pp

Syu H-H, Neelin JD, Gutzler D (1995) Seasonal and interannual variability in a hybrid coupled GCM. J Clim 8:2121-2143

Weisberg RH, Wang C (1997) A western Pacific oscillator paradigm for the El Niño-Southern oscillation. Geophys Res Lett 24:779-782

Zebiak SE, Cane MA (1987) A model El Niño/Southern Oscillation. Mon Weather Rev 115:2262-2278

Zhang R-H, Busalacchi AJ (2005) Interdecadal changes in properties of El Niño in an intermediate coupled model. J Clim 18:1369-1380

Zhang R-H, Endoh M (1992) A free surface general circulation model for the tropical Pacific Ocean. J Geophys Res 97:11237-11255

Zhang R-H, Levitus S (1997) Interannual variability of the coupled tropical Pacific ocean-atmosphereic system associated with the El Niño-Southern oscillation. J Clim 10:1312-1330

Zhang R-H, Rothstein LM (2000) Role of off-equatorial subsurface anomalies in initiating the 1991-92 El Niño as revealed by the National Centers for Environmental Prediction Ocean reanalysis data. J Geophys Res 105:6327-6339

Zhang R-H, Zebiak SE (2002) Effect of penetrating momentum flux over the surface mixed layer in a $\mathrm{Z}$-coordinate OGCM of the tropical Pacific. J Phys Oceanogr 32:3616-3637

Zhang R-H, Zebiak SE, Kleeman R, Keenlyside N (2003) A new intermediate coupled model for El Niño simulation and prediction. Geophys Res Lett. doi:10.1029/2003GL018010

Zhang R-H, Kleeman R, Zebiak SE, Keenlyside N, Raynaud S (2005a) An empirical parameterization of subsurface entrainment temperature for improved SST simulations in an intermediate ocean model. J Clim 18:350-371

Zhang R-H, Zebiak SE, Kleeman R, Keenlyside N (2005b) Retrospective El Niño forecast using an improved intermediate coupled model. Mon Weather Rev 133:2777-2802

Zhang R-H, Busalacchi AJ, DeWitt DG (2008) The roles of atmospheric stochastic forcing $(S F)$ and oceanic entrainment temperature $\left(T_{e}\right)$ in decadal modulation of ENSO. J Clim 21:674-704

Zhang R-H, Zheng F, Zhu J, Wang ZG (2013) A successful realtime forecast of the 2010-11 La Niña event. Sci Rep 3:1108. doi:10.1038/srep01108

Zheng F, Zhu J, Zhang R-H (2007) Impact of altimetry data on ENSO ensemble initializations and predictions. Geophys Res Lett 34:L13611. doi:10.1029/2007GL030451

Zheng F, Zhu J, Wang H, Zhang R-H (2009) Ensemble hindcasts of ENSO events over the past 120 years using a large number of ensembles. Adv Atmos Sci 26(2):359

Zhu J, Zhou G, Zhang R-H, Sun Z (2011) On the role of ocean entrainment temperature $\left(T_{e}\right)$ in decadal changes of El Niño/ Southern Oscillation. Ann Geophys 29:529-540. doi:10.5194/ angeo-29-529-2011

Zhu J, Zhou G, Zhang R-H, Sun Z (2012) Improving ENSO prediction in a hybrid coupled Model with an embedded entrainment temperature parameterization. J Climatol Int. doi:10.1002/ joc. 3426 